MODOLELL GONZÁLEZ, Juan Luis: "Hechos punibles en el ámbito de las prácticas deportivas. A su vez, un ejemplo de la relevancia del resultado lesivo para la configuración del injusto penal".

Polít. Crim. Vol. 16, № 31 (Junio 2021), Art. 15, pp. 408-436

[http://politcrim.com/wp-content/uploads/2021/07/Vol16N31A15.pdf]

\title{
Hechos punibles en el ámbito de las prácticas deportivas. A su vez, un ejemplo de la relevancia del resultado lesivo para la configuración del injusto penal ${ }^{*}$
}

\section{Crimes in the Context of Sports Competition: An Example of the Relevance of the Injury Result for the Configuration of the Punishable Offence}

\author{
Juan Luis Modolell González \\ Profesor de Derecho Penal, Universidad Alberto Hurtado \\ jmodolell@uahurtado.cl
}

\section{Resumen}

Fecha de recepción: 05/11/2019.

Fecha de aceptación: 09/10/2020.

\begin{abstract}
¿Por qué un hecho dañoso podría no tener la misma relevancia penal si se ejecuta durante una competencia deportiva o si se lleva a cabo fuera de ella? En el mismo sentido, ¿por qué ante lesiones graves de algunos bienes jurídicos, como la muerte de una persona cometida por otro sin justificación alguna, la respuesta social es similar independientemente del ámbito donde ocurra? Lo relativo a las lesiones del bien jurídico producidas en el contexto de una competición deportiva debe tratarse, en principio, a nivel del tipo penal aunque es necesario distinguir los casos adecuados socialmente o riesgos permitidos, y los daños irrelevantes socialmente. Así, siempre que en una competencia deportiva se produzca cualquier tipo de daño, grave o leve, producto de una actuación del autor realizada en el marco de las reglas que rigen la competición, aquel se considerará atípico en virtud de la referida adecuación social de la conducta. Por su parte, la lesión del bien jurídico producto de una infracción del reglamento deportivo podría ser atípica en función de la gravedad de aquella. Con relación a este último aspecto, lo determinante sería la magnitud de la propia lesión más que la desobediencia normativa.
\end{abstract}

Palabras clave: Deporte, reglamento, lesión, tipo penal, resultado.

\begin{abstract}
Why would a harmful act not have the same criminal relevance depending if it is committed during a sporting competition or if it takes place outside of it? On the other hand, why society reacts in similar manner when it comes to serious injuries to certain legal interests, such as the death of a person committed by another without any justification whatsoever, regardless of the setting in which the death occurs? Injuries to legal interests produced during a sporting competition should be treated, in principle, at the level of the factual elements, although it is necessary to distinguish socially appropriate cases or permitted risks, and irrelevant damages

\footnotetext{
* Agradezco al Profesor Dr. Rodrigo Coloma sus observaciones, recomendaciones y facilitación de material bibliográfico. Igualmente, agradezco la ayuda de los Profesores Dres. Lautaro Contreras y Felipe Caballero.
} 
for society. Whenever in a sporting competition any damage, serious or slight, is produced as a consequence of an activity carried out within the rules governing the competition, it will be considered atypical because of the social appropriateness of the conduct. For their part, the injury to the legal right as a consequence of an infringement of the sports regulations could only be atypical according to the seriousness of such injury. With regard to the latter, the determining factor will be the magnitude of the injury itself rather than the normative disobedience.

Keywords: sport, rules, injury, type, result.

\section{Introducción: el problema}

Durante un partido de rugby un jugador patea la cabeza de otro que está tendido en el suelo con la intención de causarle un grave daño, produciéndole la muerte. ${ }^{1}$ En un encuentro de fútbol profesional un jugador toca los genitales de otro con el fin de provocarle. En el primer caso seguramente cunde el pánico, el partido se detiene. El autor del hecho es procesado y condenado penalmente. En el segundo caso, ni siquiera expulsan al jugador del partido. El hecho es objeto de mofa en los diarios y redes sociales, celebrado por unos y censurado por otros. Tampoco se ha planteado la posibilidad de acusar penalmente al autor del hecho, salvo la aplicación de las medidas disciplinarias internas del propio deporte. Resalta la circunstancia de que si un hecho similar al primero de los descritos sucede fuera del ámbito deportivo, la reacción sería igual: se procesaría al autor y se condenaría por homicidio. Pero si una conducta como la segunda de las mencionadas ocurre fuera del partido, por ejemplo en un restaurante o en el metro, la indignación de la víctima y de la propia colectividad acarrearía el procesamiento del autor y su posible condena por un delito sexual. ${ }^{2}$

La pregunta que se plantea sería entonces, ¿por qué un hecho que podría ser castigado como un delito sexual no tiene la misma relevancia si se ejecuta durante una competencia deportiva a si se lleva a cabo fuera de ella? Por el contrario, ¿Por qué ante la muerte de una persona cometida por otro sin justificación alguna la respuesta social es similar, independientemente

\footnotetext{
${ }^{1}$ Caso Colliard (1983), de la jurisprudencia argentina: "El tribunal de Santa Fe (Argentina) no encontró ninguna circunstancia atenuante a Luis Colliard, tercera línea de un club de Paraná. Éste propinó una patada en la cabeza a Cayetano Massi, otro delantero de un club local, que falleció 19 días más tarde sin haber recuperado el conocimiento. La jugada se produjo tras un reagrupamiento en el que ambos jugadores chocaron con fuerza. Colliard saldó la disputa con una patada en la cabeza a Massi [...] El juez determinó que el golpe mortal había sido ejecutado "para causar deliberadamente daño a la víctima" cuando ambos jugadores se encontraban lejos de la acción del juego y de la pelota [...]" (Reseña del diario El País de España, disponible en https://elpais.com/diario/1983/11/03/deportes/436662017_850215.html [visitado el 29.06.2021]). En esta misma edición se alude a la agresión del italiano Paoletti, quien tres años antes arrancó una oreja a un rival después de una melée: "El talonador — jugador que hace funciones de delantero, como primera línea, para sacar los balones en touche, o fueras de banda, e intenta recuperar el balón tras las introducciones en las melées-, fue también condenado a unos meses de prisión". Menciona otros casos, RÍOS CORBACHO (2014), pp. 269 y ss.

${ }^{2}$ Como afirma PAREDES CASTAÑON (1990), p. 638, si conductas como aprisionar a un adversario o impedirle moverse, propias del judo o del fútbol americano, se produjesen fuera del campo (o del recinto de lucha), ningún juez dudaría en castigarla como un delito de coacciones.
} 


\section{Polít. Crim. Vol. 16, № 31 (Junio 2021), Art. 15, pp. 408-436 [http://politcrim.com/wp-content/uploads/2021/07/Vol16N31A15.pdf]}

del ámbito donde ocurra? En suma, ¿qué factor, o factores, determina la relevancia jurídico penal de una lesión del bien jurídico ocurrida en el contexto de una actividad deportiva?

Desde mi punto de vista, la posible respuesta a las cuestiones anteriores, que podría fungir como hipótesis de trabajo, sería la siguiente: la relevancia jurídico penal de las afectaciones de bienes jurídicos producidas en el ámbito de las actividades deportivas depende tanto de la infracción a las reglas del deporte, como de la propia gravedad de la referida lesión del objeto de los bienes jurídicos más importantes puestos en riesgo durante la competencia (vida cuya afectación siempre es relevante- y salud individual). La reacción penal en el ámbito deportivo no puede prescindir entonces de la magnitud del resultado causado.

A lo largo de este trabajo formularé una argumentación jurídico penalmente válida para explicar lo anterior. Antes, haré una breve exposición sobre cómo la doctrina penal, especialmente la chilena, aborda el problema de las lesiones del objeto del bien jurídico realizadas en el ámbito deportivo.

\section{Tratamiento sistemático}

La doctrina penal ha planteado diversas soluciones a la hora de abordar el tema de los daños producidos en competencias deportivas. En la mente de los penalistas revolotea la idea de que las infracciones jurídico penales deben ser tratadas de forma distinta si se ejecutan fuera del contexto del deporte. Por lo tanto, un primer punto sobre el cual gira la discusión radica en si las lesiones (o peligros) de bienes jurídicos producidas en el ámbito deportivo podrían ser amparadas por una causa de justificación, o bien serían supuestos de atipicidad penal.

En Chile, Garrido Montt por ejemplo considera que se trata de un supuesto de atipicidad, un caso de adecuación social aunque después agrega que son atípicas siempre que quien las sufre haya consentido en participar y se hayan respetado las reglas del juego. ${ }^{3}$ También, sostiene Couso que lo relativo a las lesiones deportivas representa un asunto de tipicidad en función del riesgo permitido y vinculado al valor del consentimiento del ofendido. ${ }^{4}$ Por otro lado, algunos de los partidarios de la solución justificante de la lesión deportiva recurren al llamado ejercicio legítimo de un derecho para fundamentar su posible impunidad. ${ }^{5}$ Incluso, otros autores aluden a una doble naturaleza, como Cousiño Mac Iver que implícitamente hace una distinción entre deportes no violentos, acciones que por lo general carecen de tipicidad y donde los resultados lesivos pudieran ser casos fortuitos o "a lo sumo, culposos", y los deportes violentos cuyas lesiones serían típicas pero se encuentran abarcadas por una causa de justificación supralegal, concretamente el reconocimiento de la actividad deportiva por el

\footnotetext{
${ }^{3}$ GARRIDO MONTT (2010), p. 184; GARRIDO MONTT (2007), pp. 205 y ss.

${ }^{4}$ COUSO (2011), p. 266.

${ }^{5}$ Por todos, NOVOA MONREAL (2005), pp. 382 y ss. CABALLERO (2000), p. 154, alude al ejercicio legítimo de un derecho como causa de justificación, pero extrañamente habla de su aplicación cuando los comportamientos se apartan de la reglamentación del deporte específico y son inadecuados al contexto en que se dan. Sobre las ventajas de concebir la exclusión de responsabilidad bajo el amparo de una causa de justificación, especialmente como ejercicio legítimo de un derecho, ver DE VICENTE RODRÍGUEZ (2010), p. 126.
} 
Estado. ${ }^{6}$ En igual sentido se pronuncia Cury (en la edición del 2011 de su Manual) quien al distinguir entre deportes violentos y no violentos aunque eventualmente peligrosos, afirma respecto de estos últimos que plantean un problema de tipicidad: "Cuando el futbolista lesiona a un rival, la cuestión, en efecto, se reduce a saber si obró de modo fortuito o bien culposa o dolosamente". ${ }^{7}$ Mientras que en los deportes violentos, recurre dicho autor a la causa de justificación de ejercicio legítimo de un derecho, siempre que las lesiones "se originen en una justa realizada conforme a las reglas reconocidas y que su gravedad no exceda los márgenes adecuados a la finalidad perseguida", ni las normas de la competición. ${ }^{8}$

Llama la atención que el sector de la doctrina chilena que distingue entre deportes violentos y no violentos, ${ }^{9}$ recurra a las causas de justificación para explicar la no punibilidad de las lesiones propias de los primeros, donde la violencia es parte de la propia actividad deportiva, mientras que para los deportes no violentos se plantee incluso el supuesto del caso fortuito (¿atipicidad?) lo que abriría la ventana a un tratamiento más benigno para estos últimos casos. ${ }^{10}$ En este sentido, la sentencia del 28 de octubre de 1998 de la Corte de Apelaciones

${ }^{6}$ COUSIÑO MAC IVER (1979), pp. 530 y ss., especialmente pp. 533 y ss. No obstante, este autor también se refiere al ejercicio legítimo de un derecho y al consentimiento.

${ }^{7}$ CURY (2011), p. 382. Énfasis en el original.

${ }^{8}$ CURY (2011) p. 383. En sentido similar, NÁQUIRA (2015), pp. 430 y ss. ETCHEBERRY (1998), p. 246, también alude a un doble tratamiento, pero entre una causa de justificación y de inculpabilidad. Así, en su obra de parte general se refiere a lo que llama "lesiones deportivas propiamente tales", es decir, las que se producen como "consecuencia de la práctica normal del deporte en conformidad a su naturaleza". En ellos distingue "si se trata de deportes que suponen el empleo de violencia física sobre los demás o no". Si no suponen el empleo de violencia, como el automovilismo, habrá un problema a dilucidar en el ámbito de la culpabilidad ya que el objeto de dicho deporte no es lesionar a nadie. En cambio, si se trata de un deporte que por su naturaleza implica el empleo de violencia física sobre otro (por ejemplo, el rugby o el boxeo), las lesiones producidas estarán amparadas por la causa de justificación de ejercicio legítimo de un derecho, si se cumplen las condiciones de que los participantes actúen voluntariamente, se respeten las reglas del juego, y el resultado no sea mayor a lo que normalmente pueda esperarse (ETCHEBERRY (1998), p. 246 y ss.; similar, ETCHEBERRY, (2004), p. 41). BULLEMORE-MACKINNON (2007b), p. 56, expresan fundamentos distintos para la impunidad, según sea la obra donde lo traten. Consideran dichos autores que las lesiones en prácticas deportivas "se trata de un problema de adecuación social de la conducta, que determina la atipicidad de la misma, todo ello basado en la costumbre social, siempre y cuando la actividad se desarrolle dentro de un razonable respeto a las reglas de la disciplina deportiva". Mientras que en la obra de parte general, afirman los aludidos: "Otra situación especial es el de las lesiones deportivas. En este ámbito, sólo puede haber justificación si la participación del afectado en la práctica deportiva ha sido voluntaria, si se han acatado las reglas del juego y si la violencia ejercida no excede de lo aceptable. En este caso, se entiende que las lesiones causadas son un mal menor que el beneficio de la práctica deportiva" BULLEMORE-MACKINNON (2007a), pp. 102 y ss.

${ }^{9}$ PAREDES CASTAÑON (1990), p. 640, se pronuncia en contra de esta diferenciación y propone hablar de deportes peligrosos y no peligrosos según "exista un pronóstico afirmativo o no a la posibilidad de que, con un comportamiento normal, se produzcan lesiones o puestas en peligro de los bienes jurídicos protegidos por ese delito o grupo de delitos". Por su parte, VENTAS SASTRE (2007), p. 3 y ss., distingue entre deportes de riesgo bilateral donde existe una confrontación directa o indirecta entre jugadores, y deportes de riesgo unilateral que son de competición individual y no existe un contacto físico entre los jugadores. De dicha distinción, afirma esta autora, se desprende que en el primer grupo de deportes se acuda a la teoría del riesgo mutuamente aceptado para explicar las lesiones producidas, mientras que para el segundo grupo haya que aludir al riesgo asumido y a sus variantes de autopuesta en peligro o imputación a la víctima.

${ }^{10}$ Salvo que se parta de una opinión como la de JIMÉNEZ DE ASÚA (1952), p. 723, quien alude a la impunidad por caso fortuito cuando la muerte, herida grave o enfermedad producidas como secuela de la actividad 


\section{Polít. Crim. Vol. 16, № 31 (Junio 2021), Art. 15, pp. 408-436 [http://politcrim.com/wp-content/uploads/2021/07/Vol16N31A15.pdf]}

de San Miguel afirmó respecto de las lesiones en deportes "no violentos" como el fútbol, lo siguiente:

"[...] la doctrina mayoritaria concluye que no se encuentran amparadas (scil. las lesiones deportivas) per se por la causal de justificación de ejercicio legítimo de un derecho (o de una profesión), por cuanto no suponen, por su propia naturaleza y finalidad, el empleo de violencia física contra la persona de otro...si se producen lesiones en el contexto de la práctica normal de una actividad deportiva de esta índole, habrá de atenderse, para resolver sobre su punibilidad, si han sido ocasionadas dolosamente, por culpa o configuran un caso fortuito. Se trata, entonces, de una cuestión de tipicidad, para quienes sitúan el dolo y la culpa en el injusto típico, como lo hace la moderna doctrina penal a partir de la teoría finalista de la acción, o de un problema de culpabilidad, según el criterio "clásico", para el cual dolo y culpa pertenecen a esta sede, a la reprochabilidad [...] más allá de la discusión dogmática resulta que el problema de las lesiones deportivas "no violentas" es ajeno a la antijuricidad como elemento caracterizador de la acción punible y, por ende, ajeno al ámbito de la justificación...No siendo posible atribuírsela al sentenciado como "obra suya" (subjetivamente), ha tenido carácter fortuito y no genera responsabilidad penal". ${ }^{11}$

Según lo expresado en la referida sentencia, si se trata de deportes violentos (aquellos que según el fallo, "suponen, por su propia naturaleza y finalidad, el empleo de violencia física contra la persona de otro") como el boxeo, el tratamiento de las lesiones producidas en dicha actividad debe hacerse bajo el foco de las llamadas causas de justificación. Sin embargo, con relación a los deportes no violentos como el fútbol, de seguirse la argumentación de la sentencia podría dársele un tratamiento más benigno a las lesiones producidas en ellos si se ubica el dolo en el tipo, o más perjudicial si se ubica el dolo en la culpabilidad. Salta a la vista que el fundamento de la sentencia comentada no puede convencer, al pasar por alto las consecuencias de la solución propuesta según la sistemática de la teoría del delito.

Obviamente, la relevancia del tratamiento sistemático dentro de la teoría del delito de las lesiones deportivas solo tiene sentido si se plantea una diferencia entre el carácter atípico de un hecho o su amparo bajo una causa de justificación. Desde mi punto de vista, independientemente de una posible validez de la teoría de los elementos negativos del tipo, ${ }^{12}$ cabe defender una distinción al menos metodológica entre el tipo y la antijuricidad (o ausencia de causas de justificación) de la siguiente forma tradicional: la exclusión de la tipicidad responde a la pregunta sobre si el hecho es por regla general admitido socialmente o representa una manifestación de la libertad de acción del individuo, incluso siendo lesivo para un bien jurídico. Por su parte, en el ámbito de la antijuricidad se determina si el hecho ya típico es permitido de manera excepcional por el ordenamiento jurídico. Por lo tanto, la relación entre el tipo y la antijuricidad sería de naturaleza "regla-excepción". ${ }^{13}$ De acuerdo a

deportiva, sean accidentes y no se haya transgredido las reglas del juego, entendiendo dicho caso fortuito como "causal que es el límite de la culpabilidad, y no [...] causa justificante".

${ }^{11} \mathrm{~N}^{\circ} 1365-96$ en Revista de Derecho y Jurisprudencia, 1998, N 3 (septiembre), parte segunda, sección cuarta, p. 261.

${ }^{12}$ Al respecto, WILENMANN (2013) pp. 126 y ss.

${ }^{13}$ Así, MEZGER (1955), p. 133. Igualmente, BALDÓ LAVILLA (1994), p. 35, pareciera sostener una relación regla-excepción entre la tipicidad y las causas de justificación al afirmar que estas últimas no presuponen una previa infracción de la norma sino una valoración previa (¿tipicidad?) "de que existe una lesión o puesta en 
ello, si se afirma que las lesiones derivadas de prácticas deportivas se encuentran amparadas por causas de justificación, habría que concluir entonces que ellos son relevantes penalmente pero se justifican excepcionalmente. Lo dudoso de esta conclusión radica en que las conductas lesivas en estos ámbitos de riesgo pueda que no ocurran de forma excepcional sino que sean consustanciales a la actividad misma, especialmente en los deportes de roce o contacto, e incluso en el caso de afectaciones de bienes ideales como el honor (piénsese en los insultos proferidos entre participantes en una competencia deportiva). ${ }^{14}$

En ese sentido, cuando se habla de "ejercicio legítimo de un derecho" como causa de justificación esgrimida para amparar los hechos lesivos en el deporte, se alude a un derecho subjetivo (o facultad) que permite a un sujeto intervenir excepcionalmente en la esfera de otro, como los tradicionales casos de "vías de hecho" citados por la doctrina penal o la facultad de corrección de los padres sobre los hijos bajo patria potestad ${ }^{15}$. Por lo tanto, esta causa de justificación implica que el propio derecho menoscaba el ámbito de libertad de otra persona o afecta un bien jurídico suyo, aunque aquel, repito, se ejerza solo excepcionalmente. Con relación al deporte habría que distinguir entre la actividad misma, verbigracia, patear o lanzar el balón, correr, etc., y la lesión producida durante el curso de aquella. La actividad deportiva entraría en el llamado libre desarrollo de la personalidad, como conducir un vehículo, dormir, expresarse, etc. Sin embargo, este ejercicio de la libertad individual puede acarrear lesiones que se consideran intrínsecos a la propia actividad libre, que en modo alguno puede confundirse con el derecho o la facultad de intervenir excepcionalmente en el ámbito de otra persona para producir alguna lesión. Solo este último caso constituye una auténtica causa de justificación. Esta distinción explicaría por qué las lesiones producidas en deportes donde la violencia es esencial, como el boxeo, deban analizarse en el ámbito del tipo y no echando mano de la referida causa de justificación de ejercicio legítimo de un derecho. En efecto, los golpes del boxeo y las lesiones consecuentes en modo alguno son

peligro de un bien jurídico -plenamente imputable a su autor- cuya valoración negativa acarreará responsabilidad penal, salvo que exista un valor de salvaguarda que la compense" (resaltado mío). En contra de la mencionada relación regularidad-excepcionalidad, por todos, WELZEL (1993), p. 97; ZAFFARONI (2002), pp. 589 y ss.

${ }^{14}$ Este razonamiento explicaría por qué tampoco puede acudirse a la institución del consentimiento para la solución del problema. En efecto, si partimos de la distinción entre el consentimiento como acuerdo (aquel que hace desaparecer la lesión del bien jurídico, por lo tanto causa de atipicidad), y el consentimiento en sentido estricto (aquel que "permite" la lesión del bien jurídico, por lo tanto causa de justificación), es claro que los daños en el deporte deberían plantearse como un ejemplo de esta última clase (sobre dicha distinción del consentimiento, véase, MIR PUIG (2015), pp. 522 y ss. -1 y ss. -). Sin embargo, justificar los daños deportivos en una especie de consentimiento tácito derivado de la propia participación en la competencia, ya que no se trata de un acuerdo, conllevaría a considerar que dichos daños se justifican excepcionalmente (causas de justificación) lo cual, como expresé supra, no ocurre precisamente en estos casos. En contra del consentimiento como institución que permite explicar la impunidad de las lesiones derivadas de prácticas deportivas, por todos, PAREDES CASTAÑ̃́N (1993), pp. 647 y ss.; MAURACH y ZIPF (1994), pp. 279 y ss. - 20-. En igual sentido, DÖLLING (1984), p. 61 para quien la solución debe basarse no en el consentimiento sino en la adecuación social. No obstante, dicho autor recurre a la solución del consentimiento cuando se trata de deportes que tienen como fin la lesión del contrincante, como sería el caso del boxeo, DÖLLING (1984), p. 64.

${ }^{15} \mathrm{Al}$ respecto, MIR PUIG (2015), pp. 500 y ss. -33 y ss.—. 


\section{Polít. Crim. Vol. 16, № 31 (Junio 2021), Art. 15, pp. 408-436 [http://politcrim.com/wp-content/uploads/2021/07/Vol16N31A15.pdf]}

excepcionales en dicha actividad, más bien forman parte del ámbito de libertad de los participantes, ámbito que es acotado por el tipo penal. ${ }^{16}$

Por otro lado, afirmar como hace un sector de la doctrina que la conducta lesiva en el ámbito deportivo estaría justificada por el reconocimiento que hace el Estado de la actividad, ${ }^{17}$ supondría admitir que es aquel quien otorga las permisiones para las actividades humanas y no que estas sean consustanciales a la propia libertad de la persona. El ejercicio de la libertad sería entonces una concesión del Estado, cuestión inadmisible en una sociedad abierta. En efecto, que el Estado regule las actividades de la población no implica necesariamente que él sea su creador. ${ }^{18}$

En razón de todo lo anterior, considero que lo relativo a las afectaciones de bienes jurídicos de cualquier clase producidas en el contexto de una competición deportiva debe tratarse, en principio, en el ámbito del tipo penal, ${ }^{19}$ aunque es necesario distinguir entre los casos adecuados socialmente o riesgos permitidos, y las lesiones de dichos bienes ocurridas por infracción de reglas deportivas pero irrelevantes socialmente. ${ }^{20}$

\section{Supuestos de adecuación social de la conducta (riesgos permitidos)}

\subsection{Principio general}

Afirmada la necesidad del análisis de las lesiones deportivas en el ámbito del tipo, debe hacerse referencia, en primer término, al supuesto de la adecuación social de la conducta deportiva o su cualidad de ser un riesgo permitido. ${ }^{21}$ Así, siempre que en una competencia

\footnotetext{
${ }^{16}$ Sobre los ámbitos de libertad de acción y el tipo penal, ver FRISCH (2004), pp. 86 y ss.

${ }^{17}$ Según v. LISZT (1908), pp. 153 y ss., especialmente p. 154, se justifican los ataques a intereses jurídicamente protegidos cuando aquellos constituyen un medio apropiado para conservar un fin protegido por el Estado, por ejemplo las lesiones causadas en el deporte "siempre que se observen las reglas del juego". En Chile, siguen esta línea, NOVOA MONREAL (2005), p. 382; POLITOFF et al. (2006), p. 289; LABATUT (2000), p. 111. En sentido similar, sobre la violencia y golpes ínsitos en el propio deporte, considera JIMÉNEZ DE ASÚA (1952), p. 737, que estarán justificadas en parte "por tratarse de actos dirigidos a un fin reconocido por el Estado, sino sobre todo por una "valuación de bienes". Es de resaltar que este autor aborda el tema de las lesiones producidas en el deporte en un capítulo denominado "Otras causas de justificación" JIMÉNEZ DE ASÚA (1952), pp. 489 y ss.

${ }^{18}$ Según PAREDES CASTAÑÓN (1993), p. 649, de la autorización estatal para la realización de actividades deportivas se deriva, a su vez, "la imposición de un deber (una exigencia) de que todos los intervinientes en dicho juego, en determinadas condiciones (concretamente, siempre que se haya prestado, expresa o tácitamente, su consentimiento libre a su intervención en el juego) soporten sin posibilidad alguna de reacción jurídica las lesiones o puestas en peligro que, respecto de sus bienes jurídico-penalmente protegidos se produzcan como consecuencia de la práctica del deporte conforme a las reglas del juego". Sobre la asunción del riesgo a la cual alude Paredes, en el ámbito del Derecho civil, ver MARBURGER (1979), p. 304, aludiendo a la jurisprudencia del Tribunal supremo alemán.

${ }^{19}$ Obviamente, un jugador puede actuar en legítima defensa para repeler la actuación antijurídica de otro competidor, así como su conducta dañosa podría ser la consecuencia de un trastorno penal transitorio.

${ }^{20}$ En este sentido, sostiene correctamente ESER (1990), p. 3 la necesidad de una solución múltiple para los casos de lesiones deportivas. Pareciera considerar las infracciones leves a las normas deportivas como una forma de adecuación social, DÖLLING, (1984), pp. 59 y ss.

${ }^{21}$ Para determinar la adecuación social en el ámbito deportivo, afirma DÖLLING (1984), pp. 61 y ss., debe distinguirse según el deporte y según el grado de organización en que el mismo se practica. En efecto, en los
} 
deportiva se produzca cualquier lesión de un bien jurídico, grave o leve, producto de una actuación del autor realizada en el marco de las reglas que rigen la competición, aquella se considerará atípica en virtud de la adecuación social de la conducta, del llamado riesgo permitido.$^{22}$ En este caso, dicha lesión producida se considera una consecuencia del riesgo que la actividad deportiva implica, de allí su falta de imputación al autor. Por ejemplo, si un boxeador mata a otro de un golpe en el curso de un combate, golpe propinado sin embargo según las reglas de la actividad, o si dos jugadores en un partido de fútbol saltan a cabecear el balón impactando entre sí produciéndose una mortal hemorragia cerebral en uno de ellos, dichos resultados no se imputarían objetivamente a su causante por tratarse de riesgos adecuados socialmente. La práctica deportiva implica esta clase de riesgos, de allí su no imputación ya que se entiende forman parte de una actividad beneficiosa para la sociedad, ${ }^{23}$ producto del ejercicio de la libertad individual. Por ello, no tiene sentido la referida distinción hecha por un sector de la doctrina entre deportes violentos y no violentos, ya que lo fundamental radica en si la actividad conlleva en sí misma el riesgo de lesión de un bien jurídico: la muerte del boxeador deriva del riesgo de la propia actividad deportiva, al igual que la grave lesión del futbolista deviene de un encontronazo propio del partido, por lo tanto se hallan en el ámbito del riesgo permitido. ${ }^{24}$

\subsection{Carácter vinculante de los reglamentos deportivos}

No obstante la aparente claridad de la conclusión anterior, ella nos conduce a un problema más profundo, concretamente el relativo al valor de los reglamentos deportivos para la imputación penal. En principio, pudiera afirmarse que su consideración será esencial en la medida en que sirven como baremos de conductas para controlar los riesgos derivados de la actividad deportiva. De este modo, en el ámbito penal deben ser tomadas en cuenta aquellas reglas de la normativa deportiva destinadas a proteger la integridad física y la vida de los competidores, especialmente mediante la sanción de las conductas infractoras.

Sin embargo, esta conclusión no es unánime en la doctrina penal. Así, se pronuncia Roxin contra el carácter vinculante de las reglas "extrajurídicas" 25 en el ámbito del Derecho penal al afirmar que no se puede atribuir a ellas igual trascendencia que a las prohibiciones de puestas en peligro abstractas realizadas por el legislador:

\footnotetext{
deportes que conllevan contacto corporal, como el fútbol o el hockey sobre hielo, el ámbito de dicha adecuación social es mayor que aquellos juegos "sin cuerpo", como el baloncesto, DÖLLING (1984), pp. 62 y ss.

${ }^{22}$ MAURACH y ZIPF (1994), pp. 280 -20-, entendiendo la adecuación social como una causa de atipicidad, MAURACH y ZIPF 1994, pp. 280 y ss. -21- -; ESER (1990), pp. 4 y ss.; también, DE VICENTE RODRÍGUEZ (2010), p. 123, no obstante las críticas expresadas por esta autora a la vaguedad que representa el referido fundamento del riesgo permitido, haciendo énfasis en que la frontera entre la impunidad y lo punible radica en la observancia de las reglas del juego — lex artis-, DE VICENTE RODRÍGUEZ (2010), p.125 y pp. 146 y ss. ${ }^{23}$ Así, GARCÍA VALDÉS (1993), pp. 976 y ss.

${ }^{24}$ En el fútbol, el reglamento de la FIFA cuando se refiere a las faltas e incorrecciones define en su regla 12 (1) el uso de la fuerza excesiva (causal de expulsión), expresando que el jugador "se excede en la fuerza empleada" y "pone en peligro la integridad física del adversario", disponibles en: https://tinyurl.com/yg78yy5m [visitado el 29/06/2021]. Por lo tanto, implícitamente la norma reconoce que hay una fuerza propia del fútbol que puede usarse, siempre y cuando no sea excesiva.

${ }^{25}$ Las cuales pudieran más bien denominarse "extra-estatales".
} 


\section{Polít. Crim. Vol. 16, № 31 (Junio 2021), Art. 15, pp. 408-436 [http://politcrim.com/wp-content/uploads/2021/07/Vol16N31A15.pdf]}

“[...] la delimitación del riesgo permitido, de la que se trata en estas "normas", no puede efectuarse por estas instituciones privadas ligadas a intereses con la misma autoridad y objetividad que por el legislador. La "norma" puede estar equivocada desde un principio o ser superada por la evolución técnica o no adecuarse al caso concreto; incluso, prescindiendo de ello, no se podrá apreciar aún un peligro jurídicopenalmente desaprobado cuando una conducta se desvía sólo de modo insignificante de una norma del tráfico o cuando la seguridad se garantiza de otro modo". ${ }^{26}$

Lo expresado por Roxin plantea dos aspectos interesantes. El primero de ellos se refiere al cuestionamiento de la fuente de la cual procede la prohibición, mientras que el segundo tiene que ver con el alcance y vigencia de la referida regla extrajurídica (extra-estatal). Sobre el primer punto, considero que, al menos en el ámbito deportivo, el propio Estado deja un amplio margen a la regulación autónoma de la competencia al reconocer (en vez de "autorizar") la misma. Por lo tanto, la autoregulación reglamentaria forma parte de la libertad de actuación de los particulares, de allí que deba reconocerse, en principio, valor jurídico a tal regulación. ${ }^{27}$ No obstante, y aquí enlazo con la segunda cuestión, el Estado puede exigir algo más para determinar la relevancia penal de la infracción de dichas reglas extrajurídicas, según los fines que persigue como ente principal de control social. ${ }^{28}$ La simple infracción de la regla extra-estatal no implica ipso jure una imputación de los resultados: el intérprete en materia penal determina la relevancia de la infracción de dichas reglas según los fines que persigue el Estado mediante la pena. En suma, la infracción de la regla extra-estatal es el punto de partida de la imputación del resultado más que "un indicio" 29 de la infracción (imprudencia). ${ }^{30}$ Sin embargo, dado que se trata de una norma extra-estatal, la relevancia

${ }^{26}$ ROXIN (1997), p. 1003 - 19-.

${ }^{27}$ El valor jurídico de las reglas deportivas (normas extra-estatales) podría ser un ejemplo del carácter abierto que RAZ atribuye al Derecho, del cual deriva la adopción de normas ajenas por parte del sistema jurídico (al respecto, RAZ (1991), pp. 177 y ss.). Dichas normas extrañas "deben ser reconocidas porque el sistema pretende respetar la manera en que la comunidad regula sus actividades, con independencia de si la misma regulación hubiera sido adoptada en otro caso", RAZ (1991), p. 178. Evidentemente, en una sociedad abierta, el Derecho (el Estado) debe aceptar, y respetar, la forma como el deporte organizado regula su actividad. En este sentido, afirma RAZ (1991), p. 177, que es característico de los sistemas jurídicos sostener y apoyar otras formas de agrupamiento social: "Los sistemas jurídicos logran esto haciendo respetar e imponiendo el cumplimiento [upholding and enforcing] de contratos, acuerdos, reglas y costumbres de individuos y asociaciones, e imponiendo el cumplimiento, mediante sus reglas de conflicto de normas, de disposiciones jurídicas de otros países, etc.".

${ }^{28}$ Además, el juez debe precisar la regla deportiva infringida ya que la vaguedad de esta puede impedir la labor de imputación. Reconoce la formulación incompleta o vaguedad de dichas reglas, MARBUGER (1979), p. 307.

${ }^{29}$ Como lo califica ROXIN (1997), p. 1003 - 19-. En igual sentido, afirma JAKOBS (1993), p. 205 - 44-: “Además de la regulación legal de áreas peligrosas de la vida, existen reglas de arte, normas técnicas y otros sistemas de regulación bastante informales. Lo que se desaprueba en estas normas no es, por supuesto, más que un indicio de la prohibición de un riesgo, ya que el consenso de una asociación profesional es en realidad una "experiencia consolidada", pero, a diferencia de una ley, no contiene ninguna valoración vinculante"

30 Al respecto, expresa MARBURGER (1979, p. 304), en el ámbito del Derecho civil, que dichas reglas deportivas representan la concreción en la actividad de un deber general de cuidado, y tienen la función de "delinear todo el complejo de comportamientos a los que se aplica el consentimiento o la asunción de riesgos". Según dicho autor, (MARBURGER, 1979, p. 305) el significado jurídico de las reglas del juego se basa no en un acto de positivización por un legislador distinto del destinatario de la norma, sino en el hecho de que el ordenamiento jurídico reconoce la disposición del individuo sobre sus bienes jurídicos y su protección. Sin embargo, añade MARBURGER (1979), p. 307, el ámbito del riesgo permitido y la participación conjunta como fundamentos últimos de la irresponsabilidad por lesiones deportivas: "En los casos de lesión del jugador, su 
penal de su infracción se vincula, como desarrollaré más adelante, a la importancia del resultado producido.

En todo caso, no son vinculantes para el intérprete las supuestas "reglas" acordadas privadamente por los participantes en una competencia deportiva, al margen de aquellas reconocidas como tales por la colectividad deportiva. Por ejemplo, si dos personas juegan una competencia de penaltis donde uno patea el balón al arco y el otro intenta detener el chut, acordando que esta última acción solo puede hacerse con la cabeza y no con cualquier parte del cuerpo (especialmente con las manos, como cualquier portero de fútbol), dicha "regla" ajena al deporte no tendrá valor alguno, por lo cual las lesiones graves ocasionadas serán atribuidas o no a su causante según los criterios generales de la imputación objetiva. ${ }^{31}$

No obstante, un aspecto fundamental a dilucidar según lo expuesto es si debe excluirse automáticamente la imputación de resultados lesivos a un deportista que los causa sin infringir el reglamento deportivo. Dicho en otras palabras, ¿excluye la falta de prohibición por la regla extrajurídica (extra-estatal) deportiva la responsabilidad del deportista? Al respecto, afirma Roxin citando literalmente la jurisprudencia del Tribunal Supremo alemán, que en "supuestos de hecho extraordinarios de puesta en peligro" las exigencias pueden ser más estrictas "que lo que resulta de las reglas concebidas para el caso medio" (BGH) ya que, como consecuencia de concebir dichas reglas extrajurídicas como indicios de la prohibiciones, no es "superfluo un examen judicial autónomo del riesgo creado. Por otro lado, el respeto de las normas del tráfico no excluye necesariamente la creación de un riesgo no permitido" 32 . Desde mi punto de vista, al menos en el ámbito deportivo, la observancia de las reglas extra-estatales que sirven para el control de riesgos en la competencia impide la imputación penal de resultados causados en la misma, precisamente porque el Derecho penal no podría exigirle al deportista una obligación adicional a la derivada de la propia regulación del deporte, so pena de paralizar la libertad de acción del atleta y, a la larga, la propia competición. Además, las normas del deporte practicado creadas para la sanción y evitación

consecuencia jurídica se basa en que el lesionado y el causante del daño, participaron conjuntamente en la competencia. De hecho, cada participante debe poder confiar en la contienda deportiva realizada según ciertas reglas que, en relación con sus compañeros (u oponentes), puede hacer uso del margen de maniobra establecido por las reglas, es decir, puede realizar los riesgos permitidos por las reglas sin exponerse a una reclamación por daños y perjuicios". Por su parte, esgrime CONTRERAS (2018), pp. 405 y ss. como criterio para apreciar el valor de las reglas extrajurídicas en el ámbito penal, la ponderación entre bienes en conflicto, concretamente entre la libertad de la actividad y la restricción de la misma como medio de evitación de daños. Aun cuando este autor atribuye carácter vinculante a las reglas extrajurídicas, según él no bastaría la simple infracción de la regla extrajurídica para que se impute un resultado al causante, ya que el intérprete debe realizar la ponderación adicional señalada (al respecto, CONTRERAS (2018), pp. 406 y ss.

${ }^{31}$ Expresa MARBURGER (1979), p. 308, en el ámbito del Derecho civil, que si los deportistas no se subordinan a las reglas del deporte, por ejemplo, porque utilizan las mismas instalaciones deportivas de forma independiente y simultánea para esquiar, hacer trampolín, patinar sobre hielo o nadar, las reglas no tendrían carácter vinculante, y el estándar de cuidado se determinaría únicamente por las reglas generales del Código Civil, aunque el juez siempre puede tenerlas en cuenta como ayuda para concretar el deber de cuidado (ídem; también conclusión de la p. 309). Desde mi punto de vista, el razonamiento del autor pudiera ser igualmente aplicable al valor de las reglas concretas acordadas por los competidores, no obstante en este último supuesto los criterios de autopuesta en peligro, e incluso el consentimiento, serían baremos preponderantes para atribuir o no el resultado lesivo.

${ }^{32}$ ROXIN (1997), p. $1003-19$-. 


\section{Polít. Crim. Vol. 16, № 31 (Junio 2021), Art. 15, pp. 408-436 [http://politcrim.com/wp-content/uploads/2021/07/Vol16N31A15.pdf]}

de daños son normas institucionales aceptadas tanto por los que participan en el juego como por el Estado que no prohíbe el mismo.

Por otra parte, dentro de la libertad de desarrollo de los individuos, las instituciones privadas organizadoras de los deportes respectivos deben tener la potestad de regular los riesgos derivados de la propia competición, precisamente por el seguimiento y control que realizan sobre la misma, y la posibilidad real de adaptar dicho control a las exigencias sociales y del propio Estado. Así, piénsese en el caso del fútbol donde hasta hace pocos años los árbitros eran más permisivos con las "faltas" ocasionadas, en contraposición a la actualidad donde, por exigencias de la FIFA, ha aumentado el uso de las amonestaciones y expulsiones del partido de los jugadores que usan la violencia antirreglamentaria. Adicionalmente, respondiendo a una de las críticas señaladas por Roxin, las normas deportivas no son disposiciones que puedan quedar desfasadas por el desarrollo de la técnica, a diferencia de otras reglas extra-estatales, precisamente porque el origen de aquellas normas procede de la entidad organizadora de la actividad recreativa.

Por último, debe señalarse que una de las características esenciales de las reglas deportivas que sirven para el control de riesgos es que no solo constituyen prohibiciones expresas, sino que además su incumplimiento acarrea una sanción, es decir, se refuerza su observancia con una consecuencias perjudicial por la infracción.

\subsection{Adecuación social, tipo objetivo y conocimientos especiales}

El análisis de la adecuación social de la conducta (riesgo permitido) se realiza en el ámbito objetivo del tipo. Por lo tanto, en este nivel no interesa considerar si el autor actuó o no dolosamente, sino si objetivamente la lesión es irrelevante o si el autor realizó su actividad dentro de los límites impuestos por las normas. Volviendo al caso del boxeador, si el golpe en la mandíbula se hace con rabia, con la intención de "sacar del combate al contrincante", pero conforme al reglamento, no se puede imputar objetivamente la grave lesión a su causante. Así, las Reglas Unificadas del Boxeo en su regla 10.1, expresa que si "un boxeador sufre una lesión como resultado de un golpe limpio y la lesión es tan severa como para terminar el combate, el boxeador lesionado perderá por nocaut técnico (TKO por sus siglas en inglés)"33. Nótese que el reglamento alude al "golpe limpio" que produce la lesión, es decir, al golpe permitido, caso en el cual la norma dispone que el lesionado pierda el combate. En modo alguno se alude a la posible responsabilidad del ganador causante de la lesión, precisamente por tratarse de un riesgo admitido por la actividad. Incluso, el lesionado carga con la consecuencia de perder el combate. Lo anterior se confirma claramente cuando la regla 10.2 del citado reglamento se refiere a las consecuencias de la lesiones "sufridas por faltas", distinguiendo entre "faltas intencionadas" (literal a) y "faltas accidentales" (letra b). En ambos supuestos, la regla se refiere a conductas antirreglamentarias (faltas), que producen

\footnotetext{
33 “La World Boxing Federation adopta e incorpora como referencia las Reglas Unificadas de la Asociación de Comisiones de Boxeo (ABC por sus siglas en inglés) actualizadas regularmente para todos los campeonatos de la World Boxing Federation" (24 de julio de 2012). Disponible en: https://tinyurl.com/yz7zy592 [visitado el 29/06/2021]
} 
lesiones, lo cual acarrea consecuencias incluso sancionatorias a su causante precisamente por haber actuado al margen de las normas. ${ }^{34}$

Desde mi punto de vista, la actitud interna del autor como la rabia o la ira, son inherentes a estas actividades. Es el llamado "calor del juego", propio del carácter competitivo de los participantes. La rivalidad del deporte conlleva a que los protagonistas actúen para vencer al oponente, lo cual pudiera explicar dicha disposición interna. Por lo tanto, habría que atender primeramente al carácter reglamentario de la conducta del deportista para imputar o no la lesión del bien jurídico producida, independientemente del aspecto subjetivo.

Sin embargo, cuestión distinta sería si el autor se aprovecha de su superioridad para hacer más daño del necesario, o si sabe de antemano que su conducta, en principio adecuada a las normas que regulan la competencia, pudiera acarrear un daño grave al adversario. ${ }^{35}$ En estos últimos supuestos considero que estaríamos ante la presencia de un conocimiento (o capacidad) especial del autor que modificaría la imputación objetiva. ${ }^{36}$ Dicho conocimiento del autor solo agrega un dato más para concretar el juicio objetivo de imputación, que

34 “10.2. Lesiones sufridas por faltas ... (a)Faltas intencionadas...1. Si una falta intencionada le causa una lesión a alguno de los boxeadores y la lesión es tan severa como para terminar el combate de inmediato, el boxeador que causa la lesión perderá por descalificación (DQ)...2. Si una falta intencionada le causa una lesión a alguno de los boxeadores y el árbitro permite que el combate continúe, el árbitro se lo notificará a los jueces y le restarán dos (2) puntos al boxeador que cometió la falta. La deducción de puntos por faltas intencionadas será obligatoria....3. Si una falta intencionada causa una lesión y esta hace que el combate se detenga en un asalto posterior, el boxeador lesionado ganará por DECISIÓN TÉCNICA si se encuentra por delante en las tarjetas de anotación de los jueces, pero el combate será EMPATE TÉCNICO si el boxeador lesionado está por debajo o empatado en las tarjetas de anotación...4. Si un boxeador se lesiona a sí mismo mientras intenta realizar una falta intencionada a su contrincante, el árbitro no tomará ninguna acción a su favor, y esta lesión será la misma que la producida por un golpe limpio...5. Si el árbitro considera que un boxeador se ha comportado de una forma antideportiva, podrá detener el combate y descalificarle... (b) Faltas accidentales...1. Si una falta accidental causa una lesión como para que el árbitro tenga que detener el combate de manera inmediata, el combate resultará en una NO DECISIÓN si las acciones son detenidas antes de que se hayan completado cuatro (4) asaltos. Se completarán cuatro (4) asaltos cuando la campana suene indicando el final del cuarto asalto...2. Si una falta accidental causa una lesión y la lesión es lo suficientemente severa como para que el árbitro detenga el combate después de cuatro (4) asaltos, el combate resultará en una DECISIÓN TÉCNICA a favor del boxeador que vaya por delante en las tarjetas de anotación de los jueces en el momento de la detención de las acciones...3. Se puntuarán los asaltos parciales o incompletos. Si no ha tenido lugar ninguna acción, el asalto deberá puntuarse como un asalto empatado. Esto es a discreción de los jueces".

${ }^{35}$ Véase la aludida regla 12 (1) del Reglamento de la FIFA, y su alusión a la fuerza "excesiva".

${ }^{36}$ Con relación al juicio de imputación objetiva en el tipo doloso de resultado material, afirma ROXIN (1997), p. 367 - 46-, la necesidad de dotar "[...] ]al observador del eventual saber especial del autor concreto...Así pues, si alguien aconseja a otro que dé un paseo, sabiendo que en el camino está al acecho un asesino, naturalmente habrá que afirmar que hay una creación de peligro, y el hecho será punible como asesinato...u...homicidio si se mata al paseante [...]". Igualmente, sostiene que para el juicio ex ante deben tenerse en cuenta las capacidades personales del autor, MALDONADO (2006), p. 35. Como es conocido, lo anterior ha sido fuente de críticas al carácter objetivo de la imputación objetiva. Al respecto, ver. las objeciones del tradicional sector "subjetivista" del Derecho Penal: por todos, KAUFMANN (1985), pp. 821 y ss.; STRUENSEE (1995), pp. 263 y ss.; CEREZO MIR (2005), p. 106. En contra del tratamiento de estos casos como problemas relativos al dolo del autor, ROXIN (1991), p. 132. Crítico de esta última opinión, ROJAS (2010), p. 250. 


\section{Polít. Crim. Vol. 16, № 31 (Junio 2021), Art. 15, pp. 408-436 [http://politcrim.com/wp-content/uploads/2021/07/Vol16N31A15.pdf]}

determinará el carácter prohibido o no de la conducta. ${ }^{37}$ En efecto, no por tomarse en cuenta un dato subjetivo deja el juicio de tener naturaleza objetiva ${ }^{38}$.

En el ejemplo del deportista que se aprovecha de su superioridad para hacer más daño del necesario, estaríamos ante un supuesto semejante al del abuso de derecho del Derecho civil, por lo tanto la conducta deja de ser permitida y el resultado sí se imputaría. Pero nótese que se atribuye no por la mala intención del autor, sino por la violación del riesgo permitido que nace de su conocimiento especial. ${ }^{39}$

\section{Hechos infractores del reglamento deportivo aunque irrelevantes penalmente}

\subsection{Elementos de la irrelevancia penal}

El otro supuesto de hechos atípicos en el ámbito deportivo es aquel donde concurre una infracción del reglamento deportivo, sin embargo se produce una lesión o peligro leves sobre el objeto del bien jurídico que hace irrelevante el hecho desde el punto de vista jurídicopenal. Los insultos entre jugadores rivales durante la competición, una patada o empujón al jugador contrario en el partido de fútbol, sin mayores consecuencias, ${ }^{40} \mathrm{o}$ el ejemplo anteriormente citado del jugador de fútbol que toca los genitales del contrario para provocarle, constituyen hechos tolerados socialmente, ${ }^{41}$ situaciones que la sociedad considera parte del propio

${ }^{37}$ La estandarización del mandato normativo se extiende a las habilidades especiales que pueda tener el autor WOLTER (1977), p. 269. Al respecto, afirma ROJAS (2010), pp. 250 y ss.: "El contenido de la norma de conducta puede variar frente a la presencia de conocimiento especial, por lo que la determinación de su infracción también. Esto significa que este conocimiento es relevante frente a la norma de conducta y, por tanto, puede ser valorado al momento de determinar la infracción de la norma", Este autor sostiene la necesidad de considerar el conocimiento especial en el ámbito de la imputación objetiva, conforme a una valoración de los intereses en conflicto - protección del bien jurídico versus ámbito de libertad-, ROJAS (2010), pp. 251 y ss. ${ }^{38}$ Así, CANCIO (2001), pp. 95 y ss.; también, CANCIO (2005), pp. 223 y ss. Más crítico en CANCIO (2004), pp. 63 y ss.

${ }^{39} \mathrm{Al}$ respecto, afirma PUPPE (2017), marginal 170, que "ningún comportamiento, ya sea manifestación de una función social o ejercido en privado, es socialmente adecuado o adecuado en sí mismo en razón de su manifestación externa, e independiente del conocimiento del actor. Como en otros casos, el principio de confianza se vuelve inaplicable si, de acuerdo con el conocimiento del autor, hay suficientes indicios en el caso individual de que su acción será causal para un hecho punible". Y agrega dicha autora: "Al igual que ocurre con cualquier otra actividad generalmente permitida, el ejercicio de una profesión puede prohibirse si es peligrosa en un caso particular y el infractor lo sabe o tiene indicios suficientes de ello, PUPPE (2017), marginal 171.

${ }^{40}$ Aunque conductas como las mencionadas en el fútbol son sancionadas disciplinariamente, sin embargo el propio reglamento de la FIFA en su regla 12 (3) admite la falta de sanción por insignificancia: "un jugador que, sin estar disputando el balón, golpee deliberadamente a un adversario o a cualquier otra persona en la cabeza o cara con la mano o el brazo, será culpable de conducta violenta a menos que la fuerza empleada sea insignificante", disponibles en: https://tinyurl.com/3uxwybh [visitado el 29/06/2021] — cursivas mías —.

${ }^{41}$ Los hechos tolerados socialmente se caracterizan porque si bien no son beneficiosos para la sociedad, esta los tolera en razón de su escasa trascendencia: "Un principio muy próximo al de la adecuación social es el de la insignificancia. Aunque algunos autores lo incluyen en aquél, puede distinguirse del mismo porque no supone la total aprobación social de la conducta, sino sólo una relativa tolerancia de la misma por su escasa gravedad. Es lo que sucede en las faltas deportivas cometidas en contra del reglamento respectivo pero que entran dentro de lo <<normal〉> en el juego (zancadillas, patadas, etc.)..." (MIR PUIG (2015), pág. 536 - 51—; MIR PUIG (1977), pp. 300 y ss.; también, MIR PUIG (1978), p. 347. Para ROXIN (1997), p. 1034 -101-, casos semejantes cabrían en el riesgo permitido. (A su vez, dice ROXIN (2002), pp. 73 y ss., el principio de insignificancia 
espectáculo deportivo. Incluso, los mismos jugadores aceptan estas conductas como parte de la actividad, de allí que no lleguen a ventilarse ante los tribunales penales aunque se infrinjan normas deportivas. ${ }^{42}$

Por lo tanto, el primer elemento a considerar para determinar la irrelevancia penal de la afectación del bien jurídico realizada en la competencia deportiva se refiere al contexto del juego en el cual se produjo. En efecto, solo un hecho producido entre los participantes de la competencia, o sobre personas directa y regularmente vinculadas a la misma (árbitros, entrenadores, jugadores suplentes, incluso el público como conglomerado caso del jugador de fútbol que después de marcar el gol hace gestos provocadores a los espectadores, etc.), puede ser calificado de irrelevante penalmente. ${ }^{43}$

Sin embargo, llama la atención, como apunta De Vicente Rodríguez, que los casos de lesiones deportivas se plantean usualmente ante los tribunales cuando se trata de competencias "amateurs", en modo alguno por duelos profesionales, ${ }^{44}$ fenómeno que también puede apreciarse en la jurisprudencia chilena (véase, las sentencias chilenas citadas en este trabajo). Desde mi punto de vista, tal circunstancia pudiera explicarse en razón de que el control normativo, e incluso social, de la práctica deportiva se relaja en la medida en que esta se ejecuta de forma menos organizada. En efecto, en un ámbito profesional el deporte usualmente va acompañado de mayores controles por parte de los entes organizadores de la actividad (federaciones, consejos disciplinarios, jueces, etc.), así como por el masivo seguimiento de espectadores (difusión por medios de comunicación, debates al respecto, etc.), lo cual se traduce a su vez tanto en más contención de los propios jugadores o participantes, como en el carácter institucional de la reacción de los entes deportivos

\footnotetext{
"permite en la mayoría de los tipos excluir desde un principio daños de poca importancia: maltrato no es cualquier tipo de daño de la integridad corporal, sino solamente uno relevante; análogamente deshonesto en el sentido del Código Penal es sólo la acción sexual de una cierta importancia, injuriosa en una forma delictiva es sólo la lesión grave a la pretensión social de respeto. Como "fuerza" debe considerarse únicamente un obstáculo de cierta importancia, igualmente también la amenaza debe ser "sensible" para pasar el umbral de la criminalidad".

${ }^{42}$ Politoff se refiere a una costumbre contra legem que ha dado origen a una norma de cultura respecto a lesiones corporales ocurridas en deportes violentos, fuera de las permitidas por este y siempre que no se trate de una infracción grosera de las normas de prudencia, fundamento de un silencio social (¿tolerancia?) respecto de aquellas. En este sentido, POLITOFF (2001), pp. 307 y ss.; similar, POLITOFF et al. (2006), p. 289, aunque aquí alude igualmente a la justificación en razón del "interés preponderante del Estado". Ver también, POLITOFF y MATUS (2003), p. 157; POLITOFF et al. (2005), p. 128 y ss.; POLITOFF et al. (2008), p. 240 y ss. Igualmente, ANTÓN ONECA (1986), p. 291 se refiere a "un elemento consuetudinario (un verdadero desuso del precepto penal)" que explica la falta de punibilidad de las lesiones deportivas producto de la infracción imprudente, e incluso dolosa, de las reglas del juego, respecto de las cuales "todos se contentan cuando más con la sanción disciplinaria impuesta por el árbitro". En contra de aceptar una costumbre contra legem en materia penal, PAREDES CASTAÑÓN (1993), p. 641. Crítico de lo que califica como "peligrosa" tolerancia social, NÁQUIRA (2015), p. 432.

${ }^{43}$ En este sentido, afirma RÍOS CORBACHO (2014), pp. 314 y ss.: "Con todo debe apuntarse que los parámetros serán las reglas del juego y que la acción se realice en circunstancias en las que no se esté jugando ( no se respete y exista una agresión claramente al margen del aspecto deportivo de la competición y el riesgo tolerado de la misma [...]".

${ }^{44}$ DE VICENTE RODRÍGUEZ (2010), pp. 156 y ss.
} 


\section{Polít. Crim. Vol. 16, № 31 (Junio 2021), Art. 15, pp. 408-436 [http://politcrim.com/wp-content/uploads/2021/07/Vol16N31A15.pdf]}

organizadores ante los daños producidos. Por su parte, el juego deportivo practicado, por ejemplo, en la calle del barrio, seguramente no contará siquiera con una persona que sirva de árbitro de la contienda, lo que dificultaría su control. No obstante, aun en este caso, la actividad se rige por normas y se ejecuta en un contexto de interacción social que debe ser considerado para la imputación de daños y la responsabilidad penal respectiva.

Como segundo elemento para determinar el carácter irrelevante del hecho debe considerarse la propia lesión o peligro producido, más que la gravedad de la infracción normativa. ${ }^{45}$ Desde mi punto de vista, el caso de los daños producidos en competencias deportivas demuestra la importancia del llamado desvalor de resultado, o mejor dicho, la relevancia de la lesión y del peligro para el objeto del bien jurídico, ${ }^{46}$ en la conformación del injusto penal en determinados ámbitos de interacción social: en el supuesto de una infracción del reglamento

45 Aunque la doctrina mayoritaria pareciera sostener lo contrario. Así, afirma ESER (1990), p. 5, que la tolerancia ante supuestos como los mencionados se basa en el principio de ponderación vinculado al carácter leve de la infracción, independientemente del tipo de resultado producido. Igualmente, resalta PAREDES CASTAÑÓN (1993), p. 655, el papel del principio de insignificancia en el ámbito de la lesiones deportivas, fundamentado en el escaso desvalor de acción. En sentido similar, expresa RÍOS CORBACHO (2014), p.312, debe tomarse en cuenta "la infracción de las reglas del juego, o sea, que la lesión de que se trate no guarde relación con el juego o cuando posea una gravedad desacostumbrada, no tanto por el resultado sino por la gravedad de la acción que lo produce". También, RÍOS CORBACHO (2011), p. 11 y ss. VENTAS SASTRE (2007), p. 17, sostiene la necesidad de considerar la "escasa entidad de la lesión" producto sin embargo de infracciones leves de las reglas del juego, ante lo cual bastaría una sanción disciplinaria según el principio de intervención mínima o ultima ratio. Igualmente, en el ámbito del Derecho Civil, expresa MARBUGER (1979), p. 303, que las infracciones ligeramente negligentes de las reglas que suceden en el celo del juego mismo, que incluso pueden ser socavadas fácilmente por los jugadores más expertos y experimentados, no deben ser imputadas a su autor. Por su parte, DÖLLING (1984), p. 62, si bien en principio pareciera recurrir a la "materialidad" de la lesión para afirmar si la misma es adecuada socialmente, aludiendo al criterio establecido en el Código penal alemán para calificar la peligrosidad de una amenaza mediante el uso de instrumento, sin embargo afirma que dicha adecuación social "debe determinarse en el momento de su realización, y no depender de consecuencias accidentales". Como opinión contraria a lo señalado, DE VICENTE RODRÍGUEZ (2010), pp. 150 y 163, se pronuncia por la irrelevancia penal cuando, aun infringiendo las reglas del juego, no se "causa lesión" alguna, o por la "escasa entidad" de las lesiones (DE VICENTE RODRÍGUEZ (2010), p. 153), añadiendo que la lesión no intencional pero producto de una infracción grave de las reglas del juego, debe ser abarcada por el Derecho penal "cuando se constate la relevancia material de la conducta con respecto a la vida o integridad de los deportistas" (DE VICENTE RODRÍGUEZ (2010), p. 153). Pareciera que implícitamente esta autora hace recaer la impunidad de la lesión en la magnitud del resultado producido. El propio ROXIN (1997), p. 1004 - 20 - expresa que la infracción de reglas deportivas per se no fundamenta la imprudencia jurídico penal, ya que el riesgo permitido es rebasado cuando dicha infracción "crea el peligro de lesiones serias". En sentido similar, CONTRERAS (2018), p. 426, al referirse a la tolerancia social ante el incumplimiento de reglas extrajurídicas que regulan ámbitos técnicos o profesionales, pareciera basar dicha tolerancia en que la inobservancia no conlleve "en la situación concreta la posibilidad de lesión para los bienes jurídicos vida o salud individual", es decir, la infracción debe representar "un peligro manifiesto para el bien jurídico, en el sentido de crear una situación de incertidumbre para el mismo".

${ }^{46}$ Es preferible utilizar la expresión desvalor de lesión o peligro en vez de desvalor de resultado, frase esta que induce a confusión y que ha facilitado las críticas por parte de los partidarios del injusto fundamentado exclusivamente en el plano subjetivo, quienes aducen que los defensores del desvalor de resultado en el injusto entienden este desde un punto de vista exclusivamente causal. Por todos, criticando a Mezger ZIELINSKI (1990), pp. 42 y ss.; y WELZEL (2002), p. 40 y ss. En efecto, referirse a la lesión o peligro del objeto del bien jurídico no implica necesariamente su confusión con la causación de un resultado material, como lo demuestra el caso de los tipos de mera actividad (por ejemplo, el hurto, allanamiento de morada, etc.) en los cuales puede existir lesión de un bien jurídico (propiedad, privacidad), sin que pueda hablarse de "una modificación del mundo exterior espacio-temporalmente separada de la conducta" (resultado causado). 
deportivo que produce un daño leve tipificado en la ley penal, pudiera decirse que no estamos en presencia de injusto penal alguno. En efecto, considero que el injusto penal, a diferencia de la infracción moral o ética, no se explica por la mera desobediencia al mandato normativo sino en función de la necesidad del castigo de dicha infracción para fines preventivos en la sociedad. Si bien la infracción de la norma es el punto de partida del ilícito penal, su conformación total depende de la importancia social del castigo vinculado a dicha infracción normativa, castigo que pudiera depender de la magnitud de la referida lesión o peligro ${ }^{47}$. Por lo tanto, la diferencia entre merecimiento de pena y necesidad de pena es superflua ya que el injusto "merecido" de pena no es tal solo por sus propias condiciones intrínsecas, sino también en razón de la propia funcionalidad del castigo.

Lo anterior se afirmaría con mayor razón cuando la desobediencia normativa se refiere a reglas de carácter extra-estatal (extrajurídicas), supuesto en el cual no puede afirmarse que la infracción acarrea automáticamente un injusto penal. El ejemplo paradigmático de lo anterior sería la usual impunidad de la tentativa del delito imprudente: este parte de la infracción de una regla de prudencia generalmente de naturaleza extra-estatal que no implica necesariamente la relevancia jurídico penal de la conducta, requiriéndose adicionalmente el resultado para afirmar el carácter penal del hecho. Aparte de la necesidad de completar la infracción de la norma extra-estatal (extrajurídica) con la relevancia del resultado, y así afirmar el referido carácter jurídico-penal del hecho, en el caso de lesiones producidas en competencias deportivas sería obvio que un castigo penal de todas las infracciones subsumibles en un tipo penal implicaría la paralización de la actividad y, a la larga, su desaparición por el efecto disuasivo de la pena. Si practicar un deporte puede acarrear responsabilidad penal a sus participantes por los frecuentes perjuicios que en él pudieran producirse, entonces sería preferible no competir. En consecuencia, atendiendo a la preponderancia de los bienes en conflicto, el Derecho penal solo puede intervenir en este ámbito de forma excepcional. ${ }^{48}$ Sin embargo, no se trata, como suele afirmarse, que el Derecho penal se detenga en las puertas del deporte, sino de realizar una adecuada valoración (ponderación) de bienes: por un lado la intervención penal a toda costa y, por el otro, el desarrollo de una actividad beneficiosa para la sociedad que frecuentemente puede acarrear lesiones de bienes jurídicos. La relevancia de la lesión referida sería el criterio determinante para dicha ponderación. ${ }^{49}$

\footnotetext{
${ }^{47}$ Lo cual no es óbice para que el Estado, aun existiendo una lesión relevante del bien jurídico, prescinda de la pena por razones de conveniencia, como lo evidencian las llamadas causas personales de exclusión de la pena o "excusas absolutorias" (verbigracia, , hurto, defraudación o daños recíprocos entre parientes y convivientes — art. 489 CP chileno_, o la llamada inviolabilidad parlamentaria, no punibilidad de los parlamentarios por votos u opiniones emitidos en ejercicio de sus funciones — primer párrafo del artículo 61 de la Constitución chilena-).

${ }^{48}$ Este aspecto pudiera confirmar que los baremos de imputación de la responsabilidad penal varían según el ámbito de libertades que se considere. Así, no serían iguales los modos de atribuir dicha responsabilidad si se trata de actividades económicas donde se persigue un fin de lucro, o de intervenciones médicas en el cuerpo humano, o de las competencias deportivas. Aunque muchos de los casos se vinculan a la ponderación entre la creación de un riesgo y el desarrollo de la libertad manifestada en la actividad, pareciera que ofrecer una solución común sería imposible.

${ }^{49}$ En todo caso, conductas infractoras como las señaladas siempre podrán ser sancionadas por los árbitros o jueces de la actividad, incluso severamente (suspensión de por vida del ejercicio de la actividad), o ser objeto
} 


\section{Polít. Crim. Vol. 16, № 31 (Junio 2021), Art. 15, pp. 408-436 [http://politcrim.com/wp-content/uploads/2021/07/Vol16N31A15.pdf]}

A su vez, a los fines de determinar la mencionada relevancia penal de la lesión del objeto del bien jurídico derivada de una conducta deportiva antirreglamentaria, deben considerarse dos factores coetáneos: la cualidad del propio bien jurídico y la cantidad de daño producido sobre su objeto. En efecto, una posible tolerancia social de las lesiones producidas en el ámbito deportivo debe partir de la clase de bien jurídico afectado. Así, no sería lo mismo afectar el honor de un competidor mediante insultos que privarle de la vida mediante una patada en la cabeza. En este sentido, la relevancia penal de las referidas lesiones debería circunscribirse a bienes jurídicos personalísimos, concretamente a la vida y salud individual, además porque estos son los bienes que usualmente pueden estar en riesgo en dichas actividades. En cuanto a bienes como el honor o la libertad de movimiento, por ejemplo, cabe afirmar que el insulto de un jugador a otro, la amenaza, los empujones, etc., son aceptados por los propios jugadores y por el público presente como parte de la contienda, del desarrollo usual de la competencia.

Como segundo factor a considerar, una vez restringida la posible relevancia en el ámbito de los intereses señalados (vida y salud individual), el análisis debe circunscribirse, especialmente con relación al segundo bien jurídico mencionado, a la posible aplicación de las modalidades de los delitos más graves previstos en el ordenamiento jurídico penal. Adelantándome a la conclusión, considero que respecto a la lesión de la vida toda modalidad de tipo penal debe ser punible, mientras que la afectación de la salud individual solo deberá ser castigada en sus más graves supuestos.

No obstante, cabe la pregunta de si en vez de considerarse la gravedad de la propia lesión bastaría tomar en cuenta la existencia de un peligro ${ }^{50}$ Personalmente creo que debe exigirse algo más que el peligro, precisamente porque los deportes de competición conviven perfectamente con ese factor. Castigar los riesgos que corre el objeto del bien jurídico en el ámbito deportivo equivaldría a sancionar penalmente las lesiones leves sucedidas en dicho ámbito. De allí que incluso la tentativa acabada o inacabada solo sería relevante si se traduce en una afectación grave del bien jurídico. Así, el jugador que patea la cabeza del jugador en el suelo con intención de causarle la muerte, fallando el intento aunque produciendo una grave lesión cerebral, respondería por homicidio frustrado. Al contrario, si falla la intencional agresión sin consecuencia alguna para el otro competidor, bastaría la sanción disciplinaria.

del reproche de los demás participantes y espectadores (poena naturalis). Ello de cierta forma evidenciaría lo innecesario de la intervención penal en ese ámbito.

${ }^{50}$ En tal sentido, alude ROXIN (1997), p. 1004 -20-, a la magnitud del peligro (riesgo) creado, para determinar la relevancia de los daños en competencias deportivas: “...la infracción de reglas de los deportes tampoco fundamenta sin más la imprudencia jurídico penal, ni siquiera cuando éstas pretenden preservar la seguridad física de los jugadores. Pues en las especialidades deportivas con enfrentamientos, como el fútbol, son inevitables y se asumen las infracciones leves de las reglas resultantes de emplearse con dureza. Incluso cuando dan lugar a un penalti se mantienen aún jurídico penalmente en el marco del riesgo permitido. Este sólo es rebasado cuando de modo contrario a las reglas se crea el peligro de lesiones serias" (cursivas mías). El propio ESER (1990), p. 5, en principio partidario de determinar la relevancia del daño deportivo en la infracción de la norma, como expresé antes, afirma que uno de los criterios para determinar dicha relevancia de las infracciones sería si "conllevan un riesgo aumentado y manifiesto, pudiendo deducirse el grado del riesgo tanto de la alta probabilidad de una lesión, como de la gravedad potencial del supuesto". En tal sentido, para dicho autor la relevancia no se determina por la infracción en sí misma, sino por el riesgo adicional unido a ella. No es casual que uno de los factores que considera ESER (1990), p. 3, para solucionar los casos de lesiones producidas en el deporte sea el resultado producido. 
Por otro lado, es importante recalcar que el hecho deportivo antirreglamentario lesivo pero irrelevante penalmente, sigue siendo un injusto aunque no un injusto de carácter penal. En consecuencia, el jugador agredido puede obrar en legítima defensa en esas circunstancias, en la medida en que para aquella la ley no suele exigir una agresión delictiva sino tan solo una "agresión ilegítima". 51

En conclusión, en el ámbito deportivo el injusto penal depende de la gravedad de la lesión del objeto de los bienes jurídicos más relevantes, como la vida —cuya afectación siempre es relevante- $-\mathrm{y}$ salud individual).

\subsection{Relevancia de la afectación a la salud producida en el ámbito deportivo (posibles criterios adicionales)}

Partiendo de que la muerte acaecida por un acto doloso o imprudente contario a las normas de la competencia deportiva siempre será objeto de sanción penal, surge la necesidad de determinar el baremo que defina la relevancia de una lesión a la salud en el enfrentamiento deportivo cuando el autor actúa al margen del reglamento. Al respecto, podrían señalarse los siguientes dos criterios a tener en cuenta para una posible impunidad.

En primer lugar, no sería relevante la lesión cuando el propio afectado responde posteriormente a la agresión injusta, siempre que cause perjuicios leves. Se trataría de una especie de compensación de agresiones, en sentido similar a las injurias y calumnias mutuas del artículo $430\left(1^{\circ}\right)$ del Código penal chileno. En este sentido, alguna sentencia chilena parece fundamentar implícitamente la falta de punibilidad, en una ponderación de agresiones mutuas ocurridas. Así, la Corte de Apelaciones de San Miguel, en sentencia del 17 de octubre de 1989, sostuvo:

"[...] la víctima de la agresión ocasionada por el reo había sido, a su vez, inmediatamente antes, el agresor de otro jugador a quien hizo perder el conocimiento de un codazo; hecho que no dio origen a la instrucción de ningún proceso criminal; conductas todas que fueron sancionadas reglamentariamente por el correspondiente Tribunal de Disciplina, quien castigó al reo y a su víctima, suspendiendo al primero por dieciséis fechas y por ocho al segundo, además de imponer una multa a los clubes de cada jugador [...] en este contexto, el hecho de autos, al igual que aquel en el que el ofendido fue el agresor, deben considerarse como constitutivos de una infracción grave a las reglas deportivas; pero no es posible calificarlos como constitutivos de un delito sancionado desde el punto de vista penal $[\ldots] " .{ }^{52}$

Si bien sería discutible que hacer perder el conocimiento a un jugador sea irrelevante penalmente, quiero resaltar el hecho de que la sentencia pareciera considerar las agresiones mutuas como uno de los factores que conducen a la impunidad del hecho. Como segundo criterio a considerar, sería irrelevante la lesión que no impida al agredido seguir realizando la actividad, que no le inhabilite.

\footnotetext{
${ }^{51}$ Primer requisito de la legítima defensa señalado en el artículo 10 (4) del CP chileno.

${ }^{52} \mathrm{~N}^{\circ}$ 507-89 en Gaceta Jurídica, 1989, Nº 112 (octubre), p.83.
} 


\section{Polít. Crim. Vol. 16, № 31 (Junio 2021), Art. 15, pp. 408-436 [http://politcrim.com/wp-content/uploads/2021/07/Vol16N31A15.pdf]}

En suma, tomando en cuenta la preponderancia de los bienes en conflicto (libertad de actuación versus punibilidad), en la esfera deportiva solo deberían castigarse las lesiones de la salud penalmente más graves previstas en el ordenamiento jurídico consecuencias de conductas antirreglamentarias. Así, en la legislación chilena el competidor deportivo solo respondería por mutilaciones (arts. 395 y 396) y por lesiones graves gravísimas (art. 397, $1^{\circ}$ ). El resto de los hechos quedaría impune, en razón de su tolerancia social (atipicidad del hecho).

\subsection{Breve excurso: azar y resultado}

Se suele objetar a la consideración del resultado para la configuración del injusto penal que ello sería darle importancia al azar en dicha conformación. ${ }^{53}$ Piénsese en el caso de que el jugador de rugby hubiese fallado la patada en la cabeza de la víctima o, por el contrario, que el jugador de fútbol al tocar los genitales del contendor lo haga de tal manera que produzca una lesión muy grave. Es obvio que el azar tiene que ver en ambos resultados, sin embargo ¿no influye la suerte en muchos ámbitos de la vida, para determinar lo adecuado o no de alguna decisión? Sobre el tema, es sabido que algún sector de la filosofía ha aceptado la llamada "suerte moral" como relevante para el juicio de responsabilidad: ${ }^{54}$

"Si negligentemente, alguien deja el grifo del baño abierto con su bebé dentro, y, cuando sube las escaleras hacia el baño, se da cuenta de que el bebé se ha ahogado, habrá hecho algo horroroso; pero, si al bebé no le ocurre nada, solo habrá sido un descuido. Quien lanza una revolución violenta contra un régimen autoritario sabe que si fracasa será responsable de mucho sufrimiento inútil, pero si triunfa estará justificado por el resultado [...] ¿Por qué no es irracional basar la evaluación moral en lo que las personas hacen, en

\footnotetext{
${ }^{53}$ En esta línea, afirma ZIELINSKI (1990), p. 143, que el simple perjuicio del bien jurídico (juicio de valor primario) no constituye el ilícito, "él es sólo un suceso jurídicamente indeseado, el resultado de una acción ilícita o bien de una casualidad”. Y agrega: “...el ilícito, como realización del objeto de la norma...no es también, precisamente, la realización del objeto del juicio de disvalor de resultado. La realización del objeto del juicio de disvalor del resultado está dada, frente al ilícito, sólo por casualidad [...]" (ZIELINSKI (1990), p. 161). Igualmente, expresa SANCINETTI (1995), p. 19, y (2001), p. 63, que el resultado exterior no puede asegurarlo el autor en el momento de motivarse, de la desautorización de la norma; él puede motivarse siempre con tendencia a una meta determinada; que la meta sea alcanzada o no, va más allá de su defecto volitivo y, por lo tanto, tampoco puede tener un lugar en el concepto de ilícito. SANCINETTI (2001), p. 90, se pronuncia por la necesidad de utilizar un criterio de selección de acciones disvaliosas que no esté sujeto a un contenido casual y arbitrario, como el azar de las consecuencias, sino que dependa en un todo -a excepción del juicio de valor, en sí mismo- de la propia decisión del autor. VILLAR (2016), pp. 246 y ss., pareciera sostener la irrelevancia de la suerte en la atribución de un resultado a un autor, aunque fundamenta su postura en la simple sustitución del término "resultado" por el de "lesión".

54 "Cuando un aspecto significativo de lo que alguien hace depende de factores que escapan a su control, y aun así continuamos tratándole a este respecto como objeto del juicio moral, esto puede llamarse suerte moral. Esta suerte puede ser buena o mala", NAGEL (2013), p. 90. En igual sentido, afirma BEADE (2017), p.31: "El vínculo entre aquello que no controlamos y el modo en que juzgamos esas acciones constituye la llamada suerte moral, sencillamente ser alabado o reprobado en parte por la mera suerte. La suerte y el control, básicamente, son conceptos contrapuestos. De este modo, todo aquello que no está bajo mi control se encuentra librado a la suerte [...]". "La moral no puede resultar inmune a la suerte...las disposiciones morales, por muy atrás que se sitúen en el área de la intención y el motivo, están tan <<condicionadas〉> como cualquier otra cosa", WILLIAMS (2013), p. 31).
} 
este sentido amplio? Esto supone considerarlas tan responsables por la contribución del destino como por las suyas propias, siempre que hayan realizado alguna contribución". ${ }^{55}$

Si la suerte pudiera ser relevante en el juicio moral, el cual pareciera girar principalmente sobre la actitud interna del autor y su capacidad de poder dominar los hechos realizados, con mayor razón en el Derecho penal sería necesario considerar factores aleatorios, especialmente porque el reproche jurídico penal tiene vinculación únicamente con hechos acontecidos en el mundo exterior, donde lo interno solo es pertinente en su relación con lo externo. En efecto, la pena no es un medio de perfección del individuo ni de expiación social, sino más bien un instrumento cuya utilidad se basa exclusivamente en su efecto social.

Igualmente, la suerte pudiera ser relevante no solo en la justificación ex post de una decisión por la cual una persona trata de lograr un fin loable haciendo acciones moralmente reprochables en abstracto, ${ }^{56}$ sino también en el ámbito jurídico penal para la eventual irresponsabilidad de alguien que persigue un fin ilícito que no logra por factores aleatorios. ${ }^{57}$ Volviendo al caso de la posible punibilidad de la tentativa en el área deportiva, ¿debe castigarse penalmente al deportista que intenta agredir al contrario, pero yerra en su propósito ${ }^{58}$ En el caso relatado al comienzo de este trabajo, ¿respondería por tentativa el jugador si hubiese fallado la patada a la cabeza, sin causar lesión alguna? Como expresé anteriormente, si se concluye afirmativamente la práctica del deporte se haría inviable a mediano plazo. En efecto, así como en algunos deportes suceden un sinnúmero de lesiones ínfimas de los bienes jurídicos, de igual manera concurren frecuentes intentos fallidos de causar lesiones graves que se explican "al calor de la competencia". Desde mi punto de vista, sancionar estos intentos no solo sería imposible en la práctica sino, además, inconveniente por entorpecer el desarrollo regular de la propia competición, de allí que la ponderación entre el castigo penal y el desarrollo de la libertad obligue a la impunidad de la tentativa que no acarrean consecuencias graves para los deportistas. Dicho de otra manera: los intentos de lesionar también serían hechos jurídico penalmente insignificantes en el ámbito deportivo si no acarrean consecuencia alguna en el agredido.

\footnotetext{
${ }^{55}$ NAGEL (2013), pp. 100 y ss. Sostiene este autor que si "la condición de control (sc., de los hechos) se aplica consistentemente, amenaza con erosionar la mayoría de las evaluaciones morales que consideramos natural hacer. De diversas maneras...las cosas por las que las personas son juzgadas moralmente no están bajo su control, o están determinadas en alguna medida por lo que está más allá de su control”, NAGEL (2013), pp. 90 y ss. En suma, “[...] admitir la importancia de la suerte implica señalar que el merecimiento no puede constituir el único criterio para construir nuestros juicios morales", BEADE (2017), p. 130. Para la descripción de las diversas tesis filosófico-penales sobre la relación entre la responsabilidad, el resultado y el castigo, BEADE (2017), pp. 45 y ss.

56 Plantea WILLIAMS (2013), pp. 37 y ss. la incidencia de la suerte en la justificación de una decisión, determinada por el éxito que acarrea la misma, refiriéndose al caso de Gauguin que abandona a su familia para dedicarse triunfalmente a la pintura.

${ }^{57}$ Personalmente considero que una de las cuestiones centrales en lo relativo a la suerte y su influencia en el Derecho Penal sería su relevancia para descartar la atribución de un resultado al autor, y en consecuencia negar su posible responsabilidad penal.

58 Al respecto, DÖLLING (1984), p. 63) pareciera pronunciarse afirmativamente cuando afirma: "Las acciones "peligrosas" también configuran el tipo de lesiones corporales si el oponente afortunadamente no sufre la grave consecuencia".
} 


\section{Polít. Crim. Vol. 16, № 31 (Junio 2021), Art. 15, pp. 408-436 [http://politcrim.com/wp-content/uploads/2021/07/Vol16N31A15.pdf]}

Sin embargo, como contrapartida a lo anterior, el jugador debe cargar con las consecuencias penales de su acto antirreglamentario si la lesión es grave. En efecto, el hecho de actuar de forma contraria al reglamento deportivo coloca al jugador en una situación según la cual debe ser responsable penalmente por la lesión (grave) producida, aunque la magnitud de este sea un hecho aleatorio. El competidor deportivo que confía en su suerte al actuar de esa forma debe contar con que la fortuna no siempre le acompañe y pueda causar un perjuicio que exija una respuesta de envergadura por parte del Estado: la pena. En tal sentido, es obvio que competir al margen del reglamento confiando que el azar le favorezca sería algo, además de irracional, absolutamente temerario. ${ }^{59}$

A esta última conclusión pudiera objetársele que se trata de una aceptación camuflada del llamado versari in re illicita, y por lo tanto una forma de responsabilidad objetiva, ${ }^{60}$ que extrae la responsabilidad penal por la lesión grave exclusivamente del carácter antirreglamentario de la conducta original. Al respecto puede responderse, en primer lugar, que la imputación del perjuicio causado, al autor que se coloca al margen del reglamento deportivo, supone que aquel sea previsible ex ante: la lesión (grave) debe haber podido ser prevista por un hombre medio situado en la posición del autor. En segundo lugar, una vez realizado ese primer nivel de imputación, se valora la relevancia ex post del daño causado para la conformación total del injusto. De tal modo, esa relevancia solo cumple el papel de descartar la imputación penal, en modo alguno su sola existencia fundamenta la imputación, como se aprecia en los casos aludidos de adecuación social y riesgo permitido. A su vez, atribuida la lesión a su autor queda intacta la posterior discusión sobre la presencia del dolo o imprudencia en el autor.

\footnotetext{
${ }^{59}$ Así, es de recordar la brutal agresión que en marzo de 2005 sufrió el futbolista Juan Arango, jugador del Mallorca de la liga española de fútbol, por parte del jugador del Sevilla Xavi Navarro: "En el minuto 40 del Mallorca-Sevilla, Arango intentó pugnar por un balón dividido, pero se encontró con el codo de Javi Navarro en el rostro. El impacto fue tremendo y el venezolano cayó desplomado al suelo. Sufrió una parada cardiorrespiratoria y tuvo que ser trasladado al hospital [...] Juan Arango, inconsciente, sufrió espasmos que hicieron temer lo peor. Tenía obstruidas las vías respiratorias por la lengua y la abundante hemorragia de su fractura en el hueso malar derecho. El médico del Mallorca, el doctor Joan Pericás, dijo en la SER minutos después: "El jugador ha sufrido un paro respiratorio, no ha llegado a perder el pulso, pero sí ha corrido peligro su vida" [...] Los primeros instantes fueron dramáticos. Rápidamente los jugadores de Mallorca y Sevilla pidieron la presencia del médico. Tras unos minutos de incertidumbre, se produjo la rápida intervención médica para conseguir que el centrocampista respirara normalmente. Se le subió en la camilla móvil en posición de costado para que no se tragara la lengua. Se le siguió atendiendo en la enfermería instantes después y luego fue trasladado en una UVI móvil a la cercana Policlínica Miramar [...] En la clínica el jugador fue sometido a un TAC para descartar posibles lesiones "estructurales”, según dijo el doctor Barturén, jefe de la UCI de Policlínica Miramar: "Ha llegado sedado y con un bajo nivel de consciencia y con ventilación espontánea. Una vez en urgencias hemos procedido a entubarlo y ponerle ventilación mecánica para poderle hacer unas pruebas diagnosticales. Sufre una fractura del malar superior derecho con sangre en el interior del seno y una herida contusa en el labio superior derecho. No hay lesión cerebral grave, pero no sabremos si está fuera de todo peligro hasta las próximas 12-24 horas, porque hay que ver qué tal despierta de la sedación" (disponible en: https://as.com/futbol/2005/03/21/mas_futbol/1111390007_850215.html [visitado el 29/06/2021]. Nótese que en este caso la vida de Arango estuvo en peligro y la agresión pudo haber sido intencional. Desde mi punto de vista, si se hubiese probado el dolo del autor, la agresión pudo haberse castigado penalmente por las graves consecuencias causadas.

${ }^{60}$ Entendiendo estrictamente por "responsabilidad objetiva" aquella que se fundamenta en la sola causación del daño ocurrido, sin datos adicionales a considerar como por ejemplo su previsibilidad.
} 
En suma, ante la cuestión de si en el Derecho penal varía el carácter injusto de un hecho según las consecuencias del mismo podría afirmarse lo siguiente: desde un punto de vista religioso, moral, e incluso ético, la valoración de un acto pudiera no depender de sus consecuencias respecto de terceros distintos del propio orden normativo. ${ }^{61}$ En cambio, la valoración de las decisiones en el ámbito del Derecho, como en la política, depende de sus efectos sociales. Concretamente, en el ámbito de un Derecho penal vinculado a los fines sociales perseguidos por la pena, la existencia de un injusto penal implica algo más que la simple infracción normativa. ${ }^{62}$ Ese plus necesario se vincula, en mi opinión, a los efectos de dicha infracción en el mundo circundante, consecuencias que caracterizarán la eventual importancia de la desobediencia normativa. De otra manera: las alarmas del aparato represivo-penal del Estado se encienden cuando algo sucede más allá de la propia violación del deber jurídico. Y ese "algo" debe tener una entidad suficiente e importante para justificar la referida reacción del Estado. Ello representa la relevancia penal del hecho ${ }^{63}$ En suma, resulta poco pertinente en el Derecho penal preguntarse sobre la conformación de un injusto

\footnotetext{
${ }^{61}$ Por ejemplo, las religiones sancionan hasta el propio pensamiento pecaminoso como lo demuestra la oración "Yo confieso" de los católicos: "Yo confieso ante Dios Todopoderoso que he pecado mucho de pensamiento, palabra, obra u omisión".

62 Incluso, la imputación objetiva frecuentemente alude a hechos adicionales a la sola desobediencia de la norma. Así, aunque el conductor infrinja groseramente una regla de tránsito (conducta relevante jurídicamente), no se le imputaría el resultado de muerte de un peatón que decide suicidarse arrojándose al vehículo. Nótese que en este ejemplo no basta considerar la actividad infractora del conductor para determinar la tipicidad penal, sino que es esencial tomar en cuenta un hecho distinto de aquella actividad: la conducta de la propia víctima. Seguramente algunos sostendrán que para la solución de un caso como el mencionado podría acudirse al criterio del fin de protección de la norma — o alcance del tipo- (véase, ROXIN (1997), pp. 377 y ss. —68 y ss.—), no obstante, aun cuando se aplique dicho criterio, es ineludible valorar un suceso distinto de la propia conducta del autor que determinará si esta constituye un hecho prohibido o no. Cuestión similar ocurriría con otro criterio de imputación objetiva como la "prohibición de regreso", formulado tradicionalmente en los siguientes términos: no es imputable objetivamente un resultado causado a una conducta cuando entre esta y aquel se ha interpuesto la conducta antijurídica de un tercero. En tal caso, la realización del resultado por el tercero que actúa antijurídicamente es su obra voluntaria, y por lo tanto es independiente de la voluntad del primer actuante, NAUCKE (1998), pp. 46 y ss.: "A" llega a un bar y deja descuidadamente su arma de fuego sobre una mesa, yéndose a conversar con unos amigos a otra parte. Inmediatamente, en otro extremo del bar comienza una discusión entre "B" y "C". "B" se percata de la existencia del arma dejada por "A" sobre la mesa y la utiliza para matar a "C". La muerte no podría ser imputada a "A", aunque este haya actuado de forma descuidada y contribuido causalmente al resultado, porque entre su conducta y el resultado se interpone un tercero que actúa antijurídicamente, además de forma dolosa. Como puede apreciarse, para imputar el resultado sería indispensable tomar en cuenta un hecho ajeno a la propia conducta prohibida.

${ }^{63}$ En este sentido, afirma MIR PUIG (2015), p. $170-35-$, que se excluye el tipo penal cuando se trata de hechos que no implican una afectación suficiente del bien jurídico, por no ser imputable su lesión a una conducta suficientemente peligrosa (falta de imputación objetiva), por consistir el bien jurídico típico en la facultad de disponer de algo por parte de su titular y existir conformidad de este (consentimiento), por ser los hechos adecuados socialmente (adecuación social) o insignificantes — principio de insignificancia-. Sobre la relevancia necesaria para la reacción penal, ver LUZÓN PEÑA (1995), pp. 30 y ss., especialmente la nota $n^{\circ}$ 43 donde afirma: "La tolerancia social (¡no la administrativa!) de la realización de un hecho bajo ciertas circunstancias es cierto que no lo justifica, pero, en un Estado democrático de Derecho, debe al menos excluir de la tipicidad penal de la acción, también en virtud de la insignificancia de la conducta". Es importante resaltar que se descarta la pena de hechos poco graves en razón de que la misma se justifica por razones de prevención. Por el contrario, si se partiera de una teoría retributiva de la pena sería mucho más complicado fundamentar la inaplicabilidad de la pena a hechos insignificantes.
} 


\section{Polít. Crim. Vol. 16, № 31 (Junio 2021), Art. 15, pp. 408-436 [http://politcrim.com/wp-content/uploads/2021/07/Vol16N31A15.pdf]}

sin tener en cuenta, simultáneamente, tanto la propia infracción normativa como la necesidad de la reacción penal.

Según lo expresado, la respuesta jurídico penal en el ámbito deportivo dependerá de la magnitud del resultado causado.

\section{Tipicidad subjetiva del hecho}

Según lo desarrollado, el hecho lesivo deportivo es atípico cuando la lesión relevante deriva de una conducta reglamentaria del competidor, y en el caso de que la conducta infractora de normas deportivas origine una lesión irrelevante. Por lo tanto, las lesiones deportivas que pudieran ameritar una respuesta penal serían la consecuencia del cruce de las variables expuestas anteriormente, es decir, cuando se infrinja objetivamente el deber normativo y, además, se ocasione una grave lesión del bien jurídico (muerte o lesiones graves en la salud de la víctima).

Dándose las variables mencionadas para la tipicidad objetiva (infracción de la regla deportiva y relevancia de la lesión), tiene sentido entonces pasar a analizar el aspecto subjetivo del hecho ${ }^{64}$, es decir, determinar el dolo ${ }^{65}$ o la imprudencia ${ }^{66}$ del autor (tipo subjetivo). ${ }^{67} \mathrm{Al}$ respecto, una reciente sentencia de instancia absolvió a un jugador de fútbol acusado de lesiones con fundamento en los siguientes argumentos:

"las lesiones al ofendido fueron producto de una jugada dentro de un partido de futbol, en la disputa de un balón [...] sin que pueda calificarse de violenta la conducta del acusado [...] no se comprobó la intención de lesionar por parte del encausado, sino más bien se acreditó que se trató de una jugada de fútbol en que se disputó un balón dividido, por el cual el acusado llegó con fuerza desmedida una fracción de segundos tarde, lo que ocasionó las lesiones del afectado [...] sin que pueda atribuirse a dicha acción dolo de lesionar a su rival". 68

Y más adelante expresa la referida decisión:

\footnotetext{
${ }^{64}$ En la doctrina chilena, MEDINA JARA (2004), p. 282, pareciera invertir el orden de análisis entre el carácter prohibido de la lesión y el elemento subjetivo del tipo, cuando afirma: "Se da en la práctica deportiva el dolo directo o eventual, lo que produce que tal comportamiento no esté cubierto por el cumplimiento del ejercicio legítimo del deber y habrá lesiones...Si no hay dolo, entonces pueden darse lesiones culposas u homicidio culposo, imputable a la falta de cuidado o falta de reglas de procedimiento [...]".

${ }^{65}$ Entendiendo el dolo en su sentido tradicional, como conjunción de conocimiento y voluntad, lo cual se adecúa al término "malicia" referido en el artículo $2^{\circ}$ del Código penal chileno.

${ }^{66}$ Dejando a salvo la discusión sobre si la imprudencia requiere algún elemento "subjetivo".

${ }^{67}$ En el caso del boxeo, la regla 10.2 de las Reglas Unificadas del Boxeo alude a la intencionalidad para distinguir dicha modalidad de infracción de la ocasionada accidentalmente. La consideración del carácter intencional o accidental del golpe parte de que el mismo haya sido antirreglamentario, es decir, constituya una "falta". Igualmente, desde un punto de vista jurídico-penal, en el caso de la muerte y lesión grave de un boxeador, solo si ellos son productos de una conducta antirreglamentaria tiene sentido examinar si se realizaron con dolo o imprudencia.

${ }^{68}$ Sentencia del 20 de febrero de 2018, Tribunal de juicio oral en lo penal de Rancagua, p. 8 (facilitada por el Profesor Felipe Caballero).
} 
"no fue posible establecer que [...], el acusado tuvo la intención de lesionar a la víctima, ya que no pudo comprobarse que el origen de las lesiones del denunciante fuera una acción dolosa $[\ldots]$, que excediere el roce habitual y posible dentro del contexto de un partido de futbol, más aun [...] los hechos se produjeron dentro de una jugada de un balón en disputa $[. .$.$] lo que exime y excluye de responsabilidad al acusado por faltar$ antijuridicidad en el hecho ilícito". ${ }^{69}$

La transcrita sentencia aborda conjuntamente lo relativo a la intención del autor (dolo) y el contexto en que se produce la lesión. Desde mi punto de vista, solo la referencia a que la lesión fue producto de la disputa de un balón durante el partido, donde el causante de la lesión llega tarde a la jugada, bastaba para afirmar la concurrencia de un riesgo propio de la actividad, por lo tanto objetivamente atípico. Incluso, la alusión en la sentencia a la falta de dolo pudiera dar a entender implícitamente que se configura el tipo objetivo.

Por otra parte, de lo anterior surge la cuestión sobre por qué el fallo descartó el delito imprudente, especialmente porque se menciona la "fuerza desmedida" con que actuó el causante de la lesión. En efecto, en el ámbito deportivo, con relación al aspecto subjetivo de los posibles tipos penales aplicables, podría darse el caso de la conducta prohibida que produce una lesión de relevancia sin que el autor haya obrado dolosamente. Así, el boxeador que al intentar golpear a su contrincante cerca del cinturón equivoca el movimiento y le golpea en los genitales causándole una muy grave lesión. En este caso, el autor actúa sin dolo pero infringe el deber de cuidado y produce un daño grave punible a título imprudente. Incluso, si hubo dolo de lesionar y se produjo la muerte, o si bien la intención era causar una lesión menor, habría que recurrir a la figura de la preterintención según la cual el autor actúa con la intención de causar un daño menor al que efectivamente produjo, pero este se le imputa en razón de que según una perspectiva ex ante una persona media situada en su posición hubiese contado con que esa lesión era de posible ocurrencia (imputación objetiva); o no imputar la lesión mayor en razón de lo imprevisible: el golpe intencionalmente dirigido a la pierna del jugador ocasiona el desprendimiento de un trombo por las várices que padece, el cual le obtura una arteria, causándole una trombosis cerebral o pulmonar que le produce la muerte.

\section{Conclusiones}

Lo relativo a las lesiones del objeto de bienes jurídicos de cualquier clase producidos en el contexto de una competición deportiva debe tratarse, en principio, en el ámbito del tipo penal aunque es necesario distinguir entre aquellos derivados del ejercicio de riesgos permitidos y los perjuicios producto de infracciones de normas deportivas pero irrelevantes socialmente.

Siempre que en una competencia deportiva se cause una lesión grave o leve, producto de una actuación del autor realizada en el marco de las reglas que rigen la competición, aquella se considerará atípica en virtud de la adecuación social de la conducta, del llamado riesgo permitido. En este sentido, la autoregulación reglamentaria forma parte de la libertad de actuación de los particulares, de allí que deba reconocerse, en principio, valor jurídico a la

${ }^{69}$ Sentencia del 20 de febrero de 2018, Tribunal de juicio oral en lo penal de Rancagua, p. 9 y 10. 
misma. No obstante, el Estado puede exigir algo más para determinar la relevancia penal de la infracción de dichas reglas. En efecto, la simple infracción de la regla extra-estatal no implica ipso jure una imputación de los resultados: el intérprete en materia penal determina la aludida relevancia de la infracción según los fines que persigue el Estado mediante la pena. Esta infracción es únicamente el punto de partida de la imputación del resultado, pero sin ella debe descartarse la aludida atribución de la lesión del bien jurídico.

El otro supuesto de hechos atípicos en el ámbito deportivo es aquel donde concurre una infracción del reglamento, sin embargo, se produce una lesión o peligro leves sobre el objeto del bien jurídico que hace irrelevante el hecho desde el punto de vista jurídico penal.

Infringidas las reglas del deporte, el injusto penal dependerá de la gravedad de la lesión del objeto de los bienes jurídicos más relevantes (vida — cuya afectación siempre es relevantey salud individual). La respuesta jurídico penal en el ámbito deportivo se vincula entonces a la magnitud del resultado.

Lo anterior en modo alguno constituye una aceptación del llamado versari in re illicita, y por lo tanto una forma de responsabilidad objetiva por el solo resultado causado. La imputación de la lesión del bien jurídico, al autor que se coloca al margen del reglamento deportivo, supone su previsibilidad ex ante. Una vez realizado ese primer nivel de imputación, se valora la relevancia ex post de dicho perjuicio causado para la conformación total del tipo objetivo. Esta última relevancia solo cumple el papel de descartar la posible imputación objetiva, en modo alguno fundamenta por sí sola la referida atribución.

Dándose la infracción de la regla deportiva y la relevancia de la lesión, tiene sentido pasar a analizar el aspecto subjetivo del hecho, es decir, determinar el dolo o la imprudencia del autor (tipo subjetivo). 


\section{Bibliografía citada}

ANTÓN ONECA, José (1986): Derecho penal (edición anotada y corregida por Hernández y Beneytez, Madrid, Akal/iure).

BALDÓ LAVILLA, Francisco (1994): Estado de necesidad y legítima defensa (Barcelona, J.M. Bosch editor).

BEADE, GUSTAVO (2017): Suerte moral, castigo y comunidad (Madrid, Marcial Pons).

BULLEMORE-MACKINNON (2007a): Curso de Derecho penal. Parte general (Santiago, LexisNexis), t. II.

BULLEMORE-MACKINNON (2007b): Curso de Derecho penal. Parte especial, (Santiago, LexisNexis), t. III.

CABALLERO, Felipe (2000): "Sistemas penales comparados. Derecho penal y actividades deportivas", en: Revista Penal. Universidad de Huelva ( ${ }^{\circ}$ 6), pp.154-156.

CANCIO MELIÁ, Manuel (2001): Líneas básicas de la teoría de la imputación objetiva (Mendoza, Ediciones Jurídicas Cuyo).

CANCIO MELIÁ, Manuel (2004): “¿Crisis del lado subjetivo del hecho?” en: LÓPEZ ZUGALDÍA (Coords.), Libro homenaje a Enrique Bacigalupo (Madrid-Barcelona, Marcial Pons), pp. 57-78.

CANCIO MELIÁ, Manuel (2005): “Algunas reflexiones sobre lo objetivo y lo subjetivo en la teoría de la imputación objetiva", en: BOLAÑOS, Mireya (Coord.), Imputación objetiva y dogmática penal (Mérida, Universidad de Los Andes), pp. 205-228.

CEREZO MIR, José (2005): Curso de Derecho penal español (Madrid, Tecnos), t. II.

CONTRERAS, Lautaro (2018): "Reglas extrajurídicas y creaciones de riesgos toleradas o desaprobadas en los delitos culposos de homicidio y lesiones", en: Política Criminal (vol. 13, no 25), pp. 387-444.

COUSIÑO MACIVER, Luis (1979): Derecho penal chileno (Santiago, Editorial Jurídica de Chile), tomo II.

COUSO, Jaime (2011): “Comentario al artículo 10 No 10 del Código penal”, en: COUSO, Jaime; HERNÁNDEZ, Héctor (Dir.) Código penal comentado (Santiago, Abeledo Perrot- UDP), pp. 260-266.

CURY, Enrique (2011): Derecho penal. Parte general (Santiago, Ediciones Universidad Católica de Chile).

DE VICENTE RODRÍGUEZ, Rosario (2010): Derecho penal del deporte (Barcelona, Bosch).

DÖLLING, Dieter (1984): "Körperverletzung im Sport", en: Zeitschrift für die gesamte Strafrechtswissenschaft ( $\mathrm{N}^{\circ}$ 96), pp. 36-65.

ETCHEBERRY, Alfredo (1998): Derecho penal. Parte general (Santiago, Editorial Jurídica de Chile), t. I.

ETCHEBERRY, Alfredo (2004): Derecho penal. Parte especial (Santiago, Editorial Jurídica de Chile), t. III.

ESER, Albin (1990): “Lesiones deportivas y Derecho penal” en: La Ley (Trad. Julia Nieto Koning, $\left.\mathrm{N}^{\circ} 2499\right)$, pp. 1-6.

FRISCH, Wolfgang (2004): Comportamiento típico e imputación de resultado (Trad. Joaquín Cuello Conteras y José Serrano González, Madrid-Barcelona, Marcial Pons). 
GARCÍA VALDÉS, Carlos (1993): "Responsabilidad por lesiones deportivas”, en: Anuario de Derecho penal y Ciencias penales (Fasc. 3), pp. 965-980.

GARRIDO MONTT, Mario (2007): Derecho penal. Parte especial (Santiago, Editorial Jurídica de Chile), t. II.

GARRIDO MONTT, Mario (2010): Derecho Penal. Parte general (Santiago, Editorial Jurídica de Chile), t. III.

JAKOBS, Günther (1993): Strafrecht. Allgemeiner Teil (Berlin-New York, W de G).

JIMÉNEZ DE ASÚA, Luis (1952): Tratado de Derecho penal (Buenos Aires, Losada), t. IV.

KAUFMANN, Armin (1985): ““"Atribución objetiva” en el delito doloso?” en: Anuario de Derecho penal y Ciencias penales (Trad. Joaquín Cuello Contreras, Fasc. 3), pp. 807826.

LABATUT, Gustavo (2000): Derecho penal (actualizado por Zenteno Vargas, Santiago, Editorial jurídica de Chile), t. I.

VON LISZT, Franz (1908): Lehrbuch des deutschen Strafrecht (Berlin, J.Guttentag).

LUZÓN PEÑA, Diego-Manuel (1993): "La relación del merecimiento de pena y de la necesidad de pena con la estructura del delito", en: Anuario de Derecho penal y Ciencias penales (Fasc. 1), pp. 21-33.

MALDONADO, Francisco (2006): "Reflexiones sobre las técnicas de tipificación de los llamados "Delitos de peligro" en el moderno Derecho penal", en: Revista de Estudios de la Justicia (No 7), pp. 23-63.

MARBURGER, Peter (1979): Die Regeln der Technik im Recht (Köln-Berlin-Bonn München, Heymanns).

MAURACH, Reinhart; ZIPF, Heinz (1994): Derecho penal. Parte general (Trad. Jorge Bofill y Enrique Aimone, Buenos Aires, Astrea) vol. I.

MEDINA JARA, Rodrigo (2004): Manual de Derecho penal (Santiago, LexisNexis, Santiago).

MEZGER, Edmund (1955): Derecho penal. Parte General (Trad. y rev. Rodríguez Muñoz, Madrid, Editorial Revista de Derecho Privado), tomo I.

MIR PUIG, Santiago (1977): "El delito de coacciones en el Código penal", en: Anuario de Derecho penal y Ciencias Penales (Tomo XXX, Fasc. 3), pp. 269-306.

MIR PUIG, Santiago (1978): “Adiciones de Derecho español al Tratado de Jescheck”, en: JESCHECK, Hans-Heinrich: Tratado de Derecho penal (Trad. y adiciones de Derecho español de Mir Puig y Muñoz Conde, Barcelona, Bosch), vol. I.

MIR PUIG, Santiago (2015): Derecho penal. Parte General (Barcelona, Reppertor).

NAGEL, Thomas (2013): "La suerte moral", en: WILLIAMS, Bernanrd; NAGEL, Thomas, La suerte moral (Trad. de Rosell, Oviedo, KRK ediciones), pp.81-118.

NÁQUIRA, Jaime (2015): Derecho penal chileno. Parte General (Santiago, Thomson Reuters), t. I.

NOVOA MONREAL, Eduardo (2005): Curso de Derecho penal chileno. Parte General (Santiago, Editorial Jurídica de Chile), t. I.

NAUCKE, Wolfgang (1998): "Sobre la prohibición de regreso en Derecho penal" en: VV.AA., La prohibición de regreso en Derecho penal (Trad. Manuel Cancio Meliá, Bogotá, Universidad Externado de Colombia). 
PAREDES CASTAÑON, José Manuel (1990): "Consentimiento y riesgo en las actividades deportivas: algunas cuestiones jurídico-penales”, en: Anuario de Derecho Penal y Ciencias Penales (Fasc. 2), pp. 633-656

POLITOFF, Sergio (2001): Derecho penal (Santiago, Cono Sur), t. I.

POLITOFF, Sergio; MATUS, Jean Pierre (2003): "Comentario al artículo $10 \mathrm{~N}^{\circ} 10$ ", en: POLITOFF, Sergio; ORTIZ, Luis (Dir.); MATUS, Jean Pierre (Coord.) Texto y comentario del Código penal chileno (Santiago, Editorial Jurídica de Chile), t. I.

POLITOFF, Sergio; MATUS, Jean Pierre; RAMÍREZ, María Cecilia (2005): Lecciones de Derecho Penal Chileno. Parte Especial (Santiago, Editorial Jurídica de Chile).

POLITOFF, Sergio; GRISOLÍA, Francisco; BUSTOS, Juan (2006): Derecho penal. Parte Especial (Santiago, Editorial Jurídica).

POLITOFF, Sergio; MATUS, Jean Pierre; RAMÍREZ, María Cecilia (2008): Lecciones de Derecho penal chileno. Parte General (Santiago, Editorial Jurídica de Chile).

PUPPE, Ingeborg (2017): "Vorbemerkungen zu §§ 13ff", en: KINDHÄUSER, Urs; NEUMANN, Ulfrid; PAEFFGEN, Hans-Ulrich; Strafgesetzbuch. Nomos Kommentar (Baden-Baden, Nomos).

RAZ, Joseph (1991): Razón práctica y normas (Trad. Juan Ruiz Manero, Madrid, Centro de Estudios Constitucionales).

RÍOS CORBACHO, José (2011): "La incidencia del Derecho penal en las lesiones deportivas", en: Revista Electrónica de Ciencia penal y Criminología (13-10), pp. 1 20.

RÍOS CORBACHO, José (2014): Violencia, deporte y Derecho penal (Madrid, Reus).

ROJAS, Luis Emilio (2010): "Lo subjetivo en el juicio de imputación objetiva: ¿aporía teórica?" en: Revista de Derecho (Vol. XXIII, No 1, julio), pp. 233-254.

ROXIN, Claus (1991): "Reflexiones sobre la problemática de la imputación en el Derecho penal” en: ROXIN, Claus, Problemas básicos del Derecho penal (Trad. Manuel Luzón Peña, Madrid, Reus), pp. 128-148.

ROXIN, Claus (1997): Derecho penal. Parte general (Trad.. y notas de Luzón, Díaz y de Vicente, Madrid, Civitas), vol. I.

ROXIN, Claus (2002): Política criminal y sistema del Derecho penal (Trad. Francisco Muñoz Conde, Buenos Aires, Hammurabi).

SANCINETTI, Marcelo (1995): Fundamentación subjetiva del ilícito y desistimiento de la tentativa (Bogotá, Temis).

SANCINETTI, Marcelo (2001): Teoría del delito y disvalor de acción (Buenos Aires, Hammurabi).

STRUENSEE, Eberhard (1995): "Acerca de la legitimación de la "imputación objetiva" como categoría complementaria del tipo objetivo", en: MAIER, Julio (Dir.); BINDER, Alberto (Coords.), El Derecho penal hoy. Homenaje al prof. David Baigún (Trad. Guariglia, Buenos Aires, Editores del Puerto) pp. 251-272.

VENTAS SASTRE, Rosa (2007): "Estudio jurídico-penal de las lesiones deportivas en el Derecho español", en: Letras Jurídicas. Revista electrónica de Derecho ( $\left.{ }^{\circ} 3\right)$, pp. $1-30$.

VILLAR, Mario (2016): Suerte penal (Buenos Aires, Didot).

WELZEL, Hans (1993): Derecho penal alemán (Trad. de la 11 a ed. alemana por Juan Bustos y Sergio Yáñez, Santiago, Edit. Jurídica de Chile). 
WELZEL, Hans (2002): "Estudios sobre el sistema del Derecho penal", en: WELZEL, Hans, Estudios de Derecho penal (Trad. de Gustavo Aboso, Montevideo-Buenos Aires, BdeF), pp. 15-120.

WILENMANN, Javier (2013): “Injusto, justificación e imputación”, en: MAÑALICH, Juan Pablo (coord.), La antijuricidad en el Derecho penal (Montevideo-Buenos Aires, BdeF), pp. 99-176.

WILLIAMS, Bernard (2013): "La suerte moral", en: WILLIAMS, Bernanrd; NAGEL, Thomas, La suerte moral (Trad. de Rosell, Oviedo, KRK ediciones), pp. 27-80.

WOLTER, Jürgen (1977): “Adäquanz- und Relevanztheorie. Zugleich ein Beitrag zur objektiven Erkennbarkeit beim Fahrlässigkeitsdelikt", en: Goltdammer's Archiv für Strafrecht, pp. 257-274.

ZAFFARONI (2002): Derecho penal. Parte General (colaboración de Alagia y Slokar, Buenos Aires, EDIAR).

ZIELINSKI, Diethart (1990): Disvalor de acción y disvalor de resultado en el concepto de ilícito (Trad. de Marcelo Sancinetti, Buenos Aires, Hammurabi).

\section{Jurisprudencia citada}

Corte de Apelaciones de San Miguel, sentencia del 17 de octubre de 1989 ( $\mathrm{N}^{\circ}$ 507-89) en: Gaceta Jurídica, N 112 (1989), octubre, p. 83.

Corte de Apelaciones de San Miguel, sentencia del 28 de octubre de 1998 ( $\left.\mathrm{N}^{\circ} 1365-96\right)$, en: Revista de Derecho y Jurisprudencia, $\mathrm{N}^{\circ} 3$ (1998), septiembre, parte segunda, sección cuarta, p. 261.

Tribunal de juicio oral en lo penal de Rancagua, sentencia del 20 de febrero de 2018. 